\title{
Isotopic measurements in water vapor, precipitation, and seawater during EUREC ${ }^{4} \mathrm{~A}$
}

Adriana Bailey ${ }^{1}$, Franziska Aemisegger ${ }^{2}$, Leonie Villiger ${ }^{2}$, Sebastian A. Los ${ }^{3}$, Gilles Reverdin ${ }^{4}$, Estefanía Quiñones Meléndez ${ }^{5}$, Claudia Acquistapace ${ }^{6}$, Dariusz B. Baranowski ${ }^{7}$, Tobias Böck ${ }^{6}$,

5 Sandrine Bony ${ }^{8}$, Tobias Bordsdorff ${ }^{9}$, Derek Coffman ${ }^{10}$, Simon P. de Szoeke ${ }^{5}$, Christopher J. Diekmann $^{11,12}$, Marina Dütsch ${ }^{13,14}$, Benjamin Ertt ${ }^{11,15}$, Joseph Galewsky ${ }^{3}$, Dean Henze ${ }^{5}$, Przemyslaw Makuch ${ }^{16}$, David Noone ${ }^{17,5}$, Patricia K. Quinn ${ }^{10}$, Michael Rösch ${ }^{18}$, Andreas Schneider ${ }^{9}, 19$, Matthias Schneider ${ }^{11}$, Sabrina Speich ${ }^{20}$, Bjorn Stevens ${ }^{21}$, Elizabeth J. Thompson ${ }^{22}$

$10 \quad{ }^{1}$ National Center for Atmospheric Research, Boulder, CO, USA

${ }^{2}$ Institute for Atmospheric and Climate Science, ETH Zurich, Zurich, Switzerland

${ }^{3}$ Department of Earth \& Planetary Sciences, University of New Mexico, Albuquerque, NM, USA

${ }^{4}$ Laboratoire d'Océanographie et du Climat: expérimentation et approches numériques (LOCEAN/IPSL), Sorbonne Université-CNRS-IRD-MNHN, Paris, France

$15{ }^{5}$ College of Earth, Ocean, and Atmospheric Sciences, Oregon State University, Corvallis, OR, USA

${ }^{6}$ Institute for Geophysics and Meteorology, University of Cologne, Köln, Germany

${ }^{7}$ Institute of Geophysics Polish Academy of Sciences, Warsaw, Poland

${ }^{8}$ Laboratoire de Météorologie Dynamique (LMD/IPSL), CNRS, Sorbonne University, Paris, France

${ }^{9}$ Netherlands Institute for Space Research, SRON, Leiden, the Netherlands

$20{ }^{10}$ NOAA Pacific Marine Environmental Laboratory (PMEL), Seattle, WA, USA

${ }^{11}$ Institute of Meteorology and Climate Research (IMK-ASF), Karlsruhe Institute of Technology (KIT), Karlsruhe, Germany

${ }^{12}$ now at Telespazio Germany GmbH, Darmstadt, Germany

${ }^{13}$ University of Vienna, Vienna, Austria

$25{ }^{14}$ University of Washington, Seattle, WA, USA

${ }^{15}$ Steinbuch Centre for Computing (SCC), Karlsruhe Institute of Technology (KIT), Karlsruhe, Germany

${ }^{16}$ Institute of Oceanology Polish Academy of Sciences, Sopot, Poland

${ }^{17}$ Department of Physics, University of Auckland, Auckland, New Zealand

${ }^{18}$ Department of Environmental Systems Science, ETH Zurich, Zurich, Switzerland

$30 \quad{ }^{19}$ Finnish Meteorological Institute, Sodankylä, Finland

${ }^{20}$ LMD/IPSL, École Normale Supérieure, CNRS, Paris, France

${ }^{21}$ Max Planck Institute for Meteorology, Hamburg, Germany

${ }^{22}$ NOAA Physical Sciences Laboratory, Boulder, CO, USA

Correspondence to: Adriana Bailey (abailey@ucar.edu)

35 Abstract. In early 2020, an international team set out to investigate trade wind cumulus and their coupling to the large-scale circulation through the field campaign EUREC ${ }^{4} \mathrm{~A}$ : ElUcidating the RolE of Clouds-Circulation Coupling in ClimAte. Focused on the western tropical Atlantic near Barbados, EUREC ${ }^{4} \mathrm{~A}$ deployed a number of innovative observational strategies, including a large network of water isotopic measurements, to study the tropical shallow convective environment. The goal of the isotopic measurements was to elucidate processes that regulate the

40 hydroclimate state - for example, by identifying moisture sources, quantifying mixing between atmospheric layers, characterizing the microphysics that influence the formation and persistence of clouds and precipitation, and providing an extra constraint in the evaluation of numerical simulations. During EUREC ${ }^{4} \mathrm{~A}$, researchers deployed seven water vapor isotopic analyzers on two aircraft, on three ships, and at the Barbados Cloud Observatory (BCO). Precipitation was also collected for isotopic analysis at BCO and from aboard four ships. In addition, three ships 
collected seawater for isotopic analysis. All told, the in situ data span the period 5 January through 22 February 2020 and cover the approximate area 6 to $16^{\circ} \mathrm{N}$ and -50 to $-60^{\circ} \mathrm{W}$. Moreover, water vapor isotope ratios were measured from a few meters to nearly $8 \mathrm{~km}$ above sea level. This paper describes the full EUREC $\mathrm{A}^{4} \mathrm{~A}$ isotopic in situ data collection - providing extensive information about sampling strategies and data uncertainties - and also guides readers to complementary remotely sensed water vapor isotope ratios. DOIs for the multiple isotopic datasets are provided in Sect. 5 Data Availability.

\section{Introduction}

In an effort to solve unanswered questions about tropical low-level clouds and their sensitivity to the larger tradewind marine environment, researchers in early 2020 carried out a multi-national, multi-platform field campaign called EUREC ${ }^{4} \mathrm{~A}$ - ElUcidating the RolE of Clouds-Circulation Coupling in ClimAte (Bony et al., 2017; Stevens et al., 2021). EUREC ${ }^{4} \mathrm{~A}$ took place in the tropical western Atlantic near the island nation of Barbados and deployed an innovative array of measurement platforms, which included multiple research aircraft and ships, aerial and oceanic drones, and ground-based stations. EUREC ${ }^{4}$ A was comprised of various research components. Some, like ATOMIC (Atlantic Tradewind Ocean-Atmosphere Mesoscale Interaction Campaign; Quinn et al., 2021; Pincus et al., 2021) and EUREC ${ }^{4} \mathrm{~A}-\mathrm{OA}$ (EUREC ${ }^{4} \mathrm{~A}$ Ocean Atmosphere interactions; http://eurec4a-oa.eu), were formally coordinated efforts that supported the deployment of the large research facilities. Others, like EUREC4A-iso, were informally coordinated through the collaborative engagement of individual investigators.

One of the ways EUREC ${ }^{4} \mathrm{~A}$-iso supported EUREC ${ }^{4} \mathrm{~A}$ 's investigations of moist processes and their effects on tradewind cloudiness was through the deployment of an expansive network of isotopic measurements in atmospheric water vapor, seawater, and precipitation. EUREC ${ }^{4} \mathrm{~A}$-iso also contributed its own set of complementary research objectives to the larger EUREC ${ }^{4} \mathrm{~A}$ mission. These were to

- link isotopic signals to patterns of cloud organization,

- refine estimates of the sub-cloud and cloud layer isotopic budgets,

- determine the importance of large-scale advection in influencing these layers,

- evaluate the roles of ocean fluxes and rain evaporation in moistening the atmosphere within cold pools, and

- characterize the coupling between tropical and extratropical water cycles.

In addition, EUREC ${ }^{4} \mathrm{~A}$-iso involves remote sensing of water vapor isotope ratios and isotopic modeling efforts, ranging from global to large-eddy simulations. The new in situ measurements thus lay the foundation for more in depth scientific investigations that combine measurements and models at distinct scales to tackle open questions about the water cycle in trade wind regions.

Because isotope ratios are sensitive to the integral of moist processes experienced by an air mass during transport (Gat 1996; Galewsky et al., 2016), they are an ideal tool for assessing the coupling between the circulation at large scales and moist processes at smaller scales. This sensitivity stems from the fact that isotopically heavy and light water molecules change phase and diffuse at distinct rates, causing the heavier molecules to reside in greater relative abundance in the condensed phase. As a result, oxygen and hydrogen isotope ratios in vapor $\left(\mathrm{i} . \mathrm{e} .{ }^{18} \mathrm{O} /{ }^{16} \mathrm{O}, \mathrm{D} / \mathrm{H}\right)$ lower with progressive condensation and rainout, while evaporation from the ocean (or another liquid reservoir) and subsequent moisture transport replenish the atmosphere with relatively heavy water. (Although the evaporative process itself discriminates against heavy water, the ocean is isotopically enriched relative to the atmosphere.) Isotope ratios thus provide a clear way to differentiate air masses that have experienced distinct water cycle histories (e.g. Noone et al., 2011; Hurley et al., 2012; Bailey et al., 2013; Aemisegger et al., 2021a) and to characterize their mixing (e.g. Noone et al., 2011; Bailey et al., 2013; Salmon et al., 2019). One outcome is the ability to differentiate boundary layer and free tropospheric air and to quantify the exchange of moisture between these layers. However, 
air-sea exchange, moisture convergence, or rain re-evaporation (Worden et al., 2007; Benetti et al., 2015; Aemisegger et al., 2015; Risi et al., 2020). And, because of the higher diffusivity of $\mathrm{HDO}$ relative to $\mathrm{H}_{2}{ }^{18} \mathrm{O}$, variations in one isotope ratio relative to the other can be used as a measure of thermodynamic disequilibrium of the environment during moisture exchange.

Following convention, we will henceforth express the oxygen and hydrogen isotope ratios in units permil (\%) as

$\delta^{18} \mathrm{O}=\left(\left[{ }^{18} \mathrm{O} /{ }^{16} \mathrm{O}\right]_{\text {obs }} /\left[{ }^{18} \mathrm{O} /{ }^{16} \mathrm{O}\right]_{\text {vsmow- }} 1\right) \times 1000$,

$\delta \mathrm{D}=\left([\mathrm{D} / \mathrm{H}]_{\mathrm{obs}} /[\mathrm{D} / \mathrm{H}]_{\mathrm{vSMOW}}-1\right) \times 1000$,

where $o b s$ indicates observed, and VSMOW is Vienna Standard Mean Ocean Water. We will also use the deuterium excess parameter, defined as $d=\delta \mathrm{D}-8 \times \delta^{18} \mathrm{O}$, to describe variations in one isotope ratio relative to the other.

While the application of water isotopes to the study of modern hydroclimate processes has been steadily growing, EUREC ${ }^{4} \mathrm{~A}$ differentiated itself from past efforts through its successful coordination of isotopic measurements across multiple platforms and through the sheer quantity of isotopic data it collected. A total of seven water vapor isotopic analyzers, sampling at $0.5 \mathrm{~Hz}$ or faster, were deployed during the campaign on two research aircraft, on three oceangoing research vessels, and at the long-term cloud observatory that operates on the eastern shores of Barbados (Stevens et al., 2016). These continuous measurements were complemented by sampling of precipitation - collected both onshore and on ships - and seawater at various depths. In addition, EUREC ${ }^{4} \mathrm{~A}$ 's isotopic measurements were integrated alongside numerous other meteorological and oceanographic measurements, designed to characterize

110 large-scale vertical motions, convective mass fluxes, cloud micro- and macrophysics, and air-sea exchange. This wealth of observational data will aid interpretation of the isotopic signals, just as the isotopic information will provide a new lens through which to evaluate microphysical and dynamical controls on trade wind cloudiness.

This paper describes the collective EUREC ${ }^{4} \mathrm{~A}$-iso in situ dataset and provides detailed information about the isotopic measurement systems deployed, the ways in which data were processed, the measurement uncertainties, and data formatting and distribution. Information is also provided that guides readers to complementary datasets, including EUREC $^{4} \mathrm{~A}$-iso remotely sensed isotope ratios, that, when used collectively with the isotopic in situ data, should advance our understanding of shallow convective cloud regimes and their role in climate.

\section{Data collection}

120 During EUREC ${ }^{4} \mathrm{~A}$, seven laser-based analyzers measured the concentration of water vapor and its isotopic composition from ground-based, airborne, and ship-based platforms. Ground-based vapor measurements were set up at the Barbados Cloud Observatory (hereafter BCO, https://barbados.mpimet.mpg.de/), airborne vapor measurements were made aboard the French ATR-42 (hereafter ATR) operated by SAFIRE (Bony et al., 2021) and the US NOAA WP-3D Orion (hereafter P-3; Pincus et al., 2021), and ship-based vapor measurements were made

125 aboard the French research vessel L'Atalante (hereafter Atalante), the German research vessel Meteor (hereafter Meteor), and the US NOAA research vessel Ronald H. Brown (hereafter Brown; Quinn et al., 2021). Precipitation samples for isotopic analysis were collected from the ground-based cloud observatory, from the three aforementioned vessels, and from the German research vessel Maria S. Merian (hereafter Merian). Seawater samples for isotopic analysis were also collected by the Meteor, the Brown, and the Atalante during their research

130 cruises. Figure 1 shows representative sampling locations of the various isotopic measurement platforms, and Fig. 2 illustrates the time periods of continuous and discrete sampling. Details of the measurement systems and in-field calibration protocols are described for each type of observational platform below. 


\subsection{Ground-based isotopic measurements}

Ground-based isotopic measurements were set up at the BCO, which served as the central land-based observatory during EUREC ${ }^{4} \mathrm{~A}$. Operated by the Max Planck Institute for Meteorology together with the Caribbean Institute for Meteorology and Hydrology, the BCO is situated on a promontory $17 \mathrm{~m}$ a.s.l. at Deebles Point $\left(13.16^{\circ} \mathrm{N}, 59.43^{\circ} \mathrm{W}\right)$, near the most windward point of the island of Barbados (Stevens et al., 2016). As a result, the BCO is directly exposed to the North Atlantic trade winds, and no island effects on the flow or atmospheric water budget have been detected previously. Moreover, clouds observed at the BCO are typical of trade-wind clouds across the tropics (Medeiros and Nuijens, 2016), making the observatory well-situated for investigating shallow convective processes that are regionally representative.

\subsubsection{Water vapor isotopic measurements at the BCO}

The BCO water vapor isotopic measurements were set up to serve as a high-frequency (1 minute) reference dataset at a location with extensive meteorological in situ and remote sensing observations, including continuous Raman

145 lidar water vapor profiling and passive remote sensing of column water vapor and condensed water. Vapor isotopic measurements at the $\mathrm{BCO}$ were made with two laser spectrometric instruments installed side-by-side (cf. Aemisegger et al. 2021): a Picarro L1115 analyzer, using cavity ring-down spectroscopy (CRDS), and a Los Gatos Research (LGR) analyzer, using off-axis integrated cavity output spectroscopy (OA-ICOS). The two instruments were installed in tandem to permit cross-validation and ensure a high-quality ground-based time series for the

150 duration of the EUREC ${ }^{4} \mathrm{~A}$ field deployment. The CRDS system measured from 13 January through 17 February 2020 (DOY 13-48), while the OA-ICOS system operated over a slightly shorter period from 18 January to 16 February 2020 (DOY 18-47) (Fig. 2).

As shown in Fig. 3, the laser spectrometers were installed in a temperature-regulated container $\left(24 \pm 2^{\circ} \mathrm{C}\right)$. Ambient air entered the container through an $8.5 \mathrm{~m}$ long $\left(12 \mathrm{~mm}\right.$ OD) heated $\left(80^{\circ} \mathrm{C}\right)$ PTFE line, $5 \mathrm{~m}$ of which resided outside the container (Fig. S1). The inlet was hooked downward near the intake and shielded from rainfall and sea spray by a funnel. A KNF pump (HN022AN.18) flushed air through the line at a flow rate of $15 \mathrm{~L} \mathrm{~min}^{-1}$. The spectrometers then sub-sampled ambient gas through a narrower ( $1 / 4$ inch OD) $0.3 \mathrm{~m}$ long isolated PTFE tube at a flow rate controlled by the instruments. This configuration resulted in a sample residence time of just $3 \mathrm{~s}$ within the inlet

160 system. However, because residence times within the instruments are much longer (e.g. $60 \mathrm{~s}$ for the CRDS system), total time delays from the intake are likely larger.

To evaluate the possibility of drift in the vapor isotopic measurements and normalize the data to the VSMOW-SLAP (Vienna Standard Mean Ocean Water - Standard Light Antarctic Precipitation; Craig, 1961; IAEA, 2017) scale, the isotopic compositions of three known liquid standards were measured daily for 20-to-60 minutes each (Supplemental Information). During the first half of the campaign (13 January to 2 February 2020, DOY 13-33), an LGR water vapor isotope standard source (WVISS) was used for producing reference gas samples from the liquid standards for both spectrometers. Due to an unfortunate breakdown of the WVISS system, a LI-COR dew point generator (LI-610) was used thereafter (until 17 February 2020, DOY 48). Because the two analyzers did not sample

170 reference gas simultaneously, the possibility exists of gap-filling the ambient time series of one analyzer with the ambient time series of the other.

\subsubsection{Precipitation isotopic measurements at the $\mathrm{BCO}$}

Precipitation samples were collected on an event basis, as well as at higher resolution (every 10 minutes) during a targeted intensive observation period of a trailing cold front on 22 January 2020 (DOY 22) (Fig. 2; see Villiger et

175 al., 2021a for a detailed overview of the event). In total, 42 rain samples were obtained between 16 January and 18 February 2020 (DOY 16-49), 26 of which were from the cold front passage. Precipitation was collected using the 
Palmex RS1 precipitation sampling system, which is specially designed to avoid post-sampling re-evaporation (Gröning et al., 2012) and has been used by the International Atomic Energy Agency (IAEA) for its Global Network of Isotopes in Precipitation (GNIP). The sampler consists of a mesh-guarded funnel, which drains rainwater through a $4 \mathrm{~mm}$ ID tube into a $3 \mathrm{~L}$ PVC collection bottle. At BCO, the sampler was installed unshielded on the top of the 2.6 $\mathrm{m}$ high container in which the vapor isotopic analyzers were housed (Fig. 3).

As soon as possible following a precipitation event, the PVC bottle containing the rainwater was removed from the sampler, immediately closed, and replaced with a new, dry PVC bottle. The amount of rain collected was weighed with a portable scale. Rainwater from the PVC bottle was transferred into $1.5 \mathrm{~mL}$ analysis vials, which were filled to the brim using disposable pipettes and thereafter hermetically sealed with parafilm. The sealed samples were stored at $20-25^{\circ} \mathrm{C}$ until analysis in the laboratory after the field experiment had concluded.

\subsection{Airborne isotopic measurements}

Airborne measurements were a key component of $\mathrm{EUREC}^{4} \mathrm{~A}$, providing an intimate look at the shallow convective systems and clouds targeted by the campaign (Stevens et al., 2021). A total of four crewed aircraft participated in EUREC $^{4} \mathrm{~A}$, two of which - the ATR and the P-3 - carried water vapor isotopic analyzers on board.

\subsubsection{ATR water vapor isotopic measurements}

The ATR flew predominantly at cloud base and in the sub-cloud layer on the eastern side of the so-called HALO circle - a $200 \mathrm{~km}$ diameter upper altitude circle, centered at $13.30^{\circ} \mathrm{N}, 57.72^{\circ} \mathrm{W}$, approximately $150 \mathrm{~km}$ to the east of Barbados. The circle was so named because the German Aerospace Center's (DLR) HALO aircraft (Konow et al., 2021) launched dropsondes around the circle in order to estimate large-scale vertical motions (Bony et al., 2017; Stevens et al., 2021). The ATR spent most of its flight hours flying repeated rectangles and L-legs in order to characterize the shallow cumulus field and to measure boundary-layer properties; it also flew a few times at cloud top and sampled the lower free troposphere during ferry legs (Bony et al., 2021). The ATR was equipped with

200 various remote-sensing (lidar, radar) and in-situ (turbulence, radiation, microphysics, stable water isotopes) instruments (Chazette et al., 2020; Brilouet et al., 2021). ATR flights were closely coordinated with HALO flights and typically lasted 4-5 hours in duration, thus making it possible to conduct two flights per day. In total, 19 flights were conducted between 25 January 2020 and 13 February 2020 (DOY 25-44).

205 To selectively target atmospheric moisture in vapor phase, the ATR flew a customized, fast-response version of Picarro's L2130-i cavity ring-down spectrometer (with nominal sampling frequency of $1 \mathrm{~Hz}$ ), which was installed behind a rearward facing inlet mounted to the starboard side of the aircraft fuselage (Fig. 4). Prior to EUREC ${ }^{4}$ A, the analyzer had been characterized in detail both in the laboratory (Aemisegger et al., 2012; Thurnherr et al., 2020) and during research flights over the Mediterranean in 2012 (Sodemann et al., 2017). The inlet consisted of a $1 / 4$ inch OD

210 stainless steel gooseneck ( $0.3 \mathrm{~m}$ long), connected to a $1.5 \mathrm{~m}$ long, $10 \mathrm{~mm}$ ID PTFE tube, which was heated to $80^{\circ} \mathrm{C}$ (Fig. S2). A $0.2 \mu \mathrm{m}$ PTFE vent filter was installed at the end of the inlet line to prevent particles from entering the laser spectrometer. A KNF membrane pump (HN022AN.18) flushed the inlet line at a rate of 13 SLPM, while a second pump (KNF N920AP.29.18) directed a sub-sample (at a flow rate of $280 \mathrm{~mL} \mathrm{~min}^{-1}$ ) to the isotopic analyzer through a thermally isolated, $0.2 \mathrm{~m}$ long, $1 / 4$ inch OD PTFE line. The resulting residence time of the sample (at sea

215 level) totaled $10 \mathrm{~s}$, of which $1 \mathrm{~s}$ was attributable to the inlet system and $9 \mathrm{~s}$ to the instrument.

ATR isotopic measurements were calibrated during the campaign using a Picarro Standards Delivery Module (SDM), which was installed on the aircraft instrument rack. The SDM delivers a thin stream of liquid water of known isotopic composition into a vaporizer, which, in turn, converts the stream to gas phase. Liquid standards were selected whose isotope ratios bracketed the observed ranges of the lower free troposphere and the cloud and subcloud layers (Supplemental Information). 
Each flight day, 2-3 liquid standards were run either before or after the day's flights. When time permitted, the SDM was also run during refueling between the morning and afternoon flights. An additional four calibration checks were performed in flight. Importantly, the airborne calibrations did not show a significant difference in either mean or standard deviation compared to the ground-based calibrations. This lent confidence to the decision to include the ground-based calibrations in evaluating biases and uncertainty in the airborne data. In total, 32 calibration checks were performed and used to assess instrument drift and normalize the data to the VSMOW-SLAP scale. Aliquots of the liquid standards were also taken regularly during the campaign to survey any potential drift in the standards 230 themselves.

\subsubsection{P-3 water vapor isotopic measurements}

Compared to the ATR, the P-3 flew over a larger altitude range and traversed a wider geographic area, typically east, and frequently upwind, of the HALO circle (Pincus et al., 2021). Eleven total flights were conducted over the period 17 January to 11 February 2020 (DOY 17-42). Most flights, which were about 8 hours in duration, included a circle in the mid-troposphere to launch dropsondes, a rake pattern to deploy Airborne EXpendable BathyThermographs (AXBTs), and vertically stacked level legs, ascending from 150 m.a.s.l, through cloud, to cloud top. Particularly relevant for water isotopic measurements, there were also continuous slantwise ascents and descents. Together with the stacked cloud passes and takeoffs and landings, these slantwise traverses provide several snapshots per flight of the isotopic profile of the convective environment.

Like the ATR, the P-3 flew a customized, fast-response version of Picarro's L2130-i cavity ring-down spectrometer (with $5 \mathrm{~Hz}$ nominal sampling frequency). The analyzer was installed behind a rearward-facing inlet mounted to the starboard side of the aircraft fuselage. The analyzer sampled from a National Center for Atmospheric Research HIAPER Modular Inlet (NCAR HIMIL), through a $2.1 \mathrm{~m}$ long, $1 / 4$ inch OD copper tube. The setup is described in greater detail in Pincus et al. (2021) and shown in Fig. 4. The inlet was heated to $40^{\circ} \mathrm{C}$ during the first two flights and increased to $48^{\circ} \mathrm{C}$ thereafter once the heat controller's precision was confirmed (no change in measurement accuracy was detected as a result). Mass flow through the copper tube was controlled by the spectrometer at 0.6 SLPM (with reference temperature $298.15 \mathrm{~K}$ and reference pressure $1013.25 \mathrm{hPa}$ ), resulting in typical time delays through the inlet of $(3.4 \pm 0.3) \mathrm{s}$ near sea level and $1.4 \mathrm{~s}$ near the highest flight altitudes of about $400 \mathrm{hPa}$ (Pincus et al., 2021).

The repeatability of the P-3 isotopic measurements was spot checked by manually injecting liquid standards directly into a vaporizer during three non-flight days. A rotation of five liquid standards was used, with isotopic values spanning $[-45.41,-0.28] \%$ for $\delta^{18} \mathrm{O}$ and $[-355.18,1.60] \%$ for $\delta \mathrm{D}$. The analyzer also sampled from a rack-mounted

255 LI-COR $610 \mathrm{dew}$ point generator usually twice per flight for approximately 10 minutes each time. However, the reference gas generated by the LI-COR proved unstable over the course of the campaign and was therefore not used to evaluate instrumental drift.

\subsection{Ship-based isotopic measurements}

The four ships that participated in EUREC ${ }^{4} \mathrm{~A}$ - each measuring water isotope ratios in some form - covered two principal geographic regions: "Tradewind Alley", the name given to a corridor stretching approximately eastward from Barbados to the Northwest Tropical Atlantic Station (NTAS), an air-sea flux measuring buoy station near $15^{\circ} \mathrm{N}, 51^{\circ} \mathrm{W}$, and the "Boulevard des Tourbillons", a name given to the region contouring the northern coast of South America (Quinn et al., 2021; Stephan et al., 2021; Stevens et al., 2021). The Meteor and Brown stayed close to Tradewind Alley, providing a valuable ground-up perspective for the EUREC ${ }^{4} \mathrm{~A}$ aircraft flying overhead. In colder waters near the North Brazil Current and to investigate mesoscale ocean eddies, freshwater inputs from the 
Amazon and Orinoco discharges, and deep convective outflows from the Intertropical Convergence Zone. The Merian also collected a number of rain samples within Tradewind Alley. Examples of water vapor and precipitation isotopic sampling installations aboard the ships are shown in Fig. 5.

270

\subsubsection{Water vapor isotopic measurements at sea}

\section{Meteor}

From 18 January until 22 February 2020 (DOY 18-53), the Meteor operated a 1 Hz CRDS-based Picarro L2130-i analyzer to the east of Barbados. During most of this period, the Meteor sampled regularly along a north-south transect defined by the $57.24^{\circ} \mathrm{W}$ meridian within the eastern portion of the HALO circle. Exceptions to this were, 0400-1100 UTC on 18 January (DOY 18) and 0900-1300 UTC on 19 February (DOY 50) when the ship was stationed just 1 nautical mile upwind of the BCO, as well as 1300-2300 UTC on 19 February (DOY 50) when the ship was stationed just offshore of Bridgetown port.

The analyzer aboard the Meteor was housed in the Air-Chemistry Laboratory, the highest enclosed, temperaturecontrolled deck on the ship. The analyzer sampled ambient air $\sim 20.3$ m.a.s.l. from an inlet affixed to a bow-facing railing above the Air-Chemistry Laboratory and below the main meteorological instrument mast. The inlet was housed in a downward-facing funnel to limit contamination by rainwater and sea spray. The $5 \mathrm{~m}$ long PTFE inlet line was heated to $45^{\circ} \mathrm{C}$ and insulated with polyethylene foam and foil tape. A $0.2 \mu \mathrm{m}$ PTFE aerosol filter was included to limit particle debris.

A rotation of four liquid water standards was used to check for instrument drift daily during the cruise and normalize the data to the VSMOW-SLAP scale. The standards spanned the expected ambient range (consisting of values of $3.26 \%_{0} \pm 0.12,-2.79 \%_{0} \pm 0.12,-17.85 \%_{0} \pm 0.16$, and $-20.97 \%_{0} \pm 0.16$ for $\delta^{18} \mathrm{O}$ and $-13.12 \%_{0} \pm 0.57,-17.44 \%_{0} \pm 0.56$, $-132.23 \% \pm 0.82$, and $-158.13 \% \pm \pm 0.82$ for $\delta D$ ). The standards were delivered to the analyzer in gas phase using a Picarro SDM and vaporizer. Each day, two standards were measured for 10 minutes each, and a new standard was swapped in every four days to complete the rotation.

\section{Brown}

The Brown, like the Meteor, ventured predominantly within Tradewind Alley but tended to sample farther to the east - as far as $51^{\circ} \mathrm{W}$ - in order to provide information about the atmosphere-ocean system upwind of the primary EUREC ${ }^{4}$ A study region (Quinn et al., 2021). The Brown was stationed in port at Bridgetown, Barbados from 1215 UTC on 26 January until 2215 UTC on 28 January (DOY 26-28) and from 1900 UTC on 4 February until 1600 UTC on 6 February (DOY 35-37).

To measure the isotopic composition of near-surface water vapor, the Brown operated a customized $5 \mathrm{~Hz}$ Picarro L2130-i analyzer from 26 January to 10 February 2020 (DOY 26-41). The analyzer aboard the Brown was housed within a measurement container alongside aerosol instrumentation on the $\mathrm{O} 2$ deck of the ship, two levels above the main deck (Quinn et al., 2021). All instruments within the container sampled from a heated mast whose coneshaped nozzle was mounted 18 m.a.s.l. (Bates et al., 2002). Air was pumped through the nozzle and down the $0.2 \mathrm{~m}$ diameter mast at a rate of $1000 \mathrm{~L} \mathrm{~min}^{-1}$. The isotopic analyzer drew a sub-sample of air from the base of the mast through a $1 / 4$ inch OD, $3 \mathrm{~m}$ long copper tube heated to $50^{\circ} \mathrm{C}$ and insulated with polyethylene foam.

No drift checks were performed during the duration of the cruise. Instead, the accuracy of the isotopic measurements was checked on the day the analyzer was installed on the ship (26 January 2020, DOY 26). The calibration was performed by manually injecting three liquid water standards - with values spanning $-22.38 \%$ and $-1.89 \%$ for $\delta^{18} \mathrm{O}$ and $-163.50 \%$ and $-8.37 \%$ for $\delta \mathrm{D}$ - into a vaporizer. Each standard was injected 5-6 times, but only the last three 
injections were used to normalize the instrument to the VSMOW-SLAP scale (in order to minimize the effects of hysteresis). Complications in retrieving the instrument from the aerosol measurement container prevented a timely post-campaign verification of the instrument calibration.

\section{Atalante}

315 The Atalante, which sailed predominantly in the Boulevard des Tourbillons, operated a 0.5 Hz Picarro L2120-i analyzer from 23 January to 17 February 2020 (DOY 23-48). Because there was not enough heated line to reach the mast where the ship's main meteorological station was located, the isotopic analyzer was placed in an airconditioned space to the back of the bridge. There, it sampled through a $10 \mathrm{~m}$ long line of $10 \mathrm{~mm}$ diameter PFA tubing, heated to $40^{\circ} \mathrm{C}$, which was attached to the railing on top of the bridge, close to the port side. Ambient air was pumped through the line at $6 \mathrm{~L} \mathrm{~min}^{-1}$.

To check for possible instrumental drift, a single liquid standard was measured daily during the cruise, except on 27 and 28 January 2020 (DOY 27-28). The liquid standard (with $\delta^{18} \mathrm{O}$ and $\delta \mathrm{D}$ values of -14.95 and $-109.7 \%$, respectively) was delivered to the analyzer in gas phase using an autosampler paired with a Picarro vaporizer. For each daily calibration check, the autosampler injected the standard into the vaporizer 15 times, consuming about 2.5 hours of measurement time each day.

\subsubsection{Precipitation isotopic measurements at sea}

All four research vessels collected rainwater for offline isotopic analysis after the campaign. The Meteor, the Atalante, and the Merian used the same Palmex RS1 rain sampler as installed at BCO (Gröning et al., 2012). The rain sampler on the Brown was slightly different in nature, composed of a large funnel, screwed to a pear-shaped conical separatory funnel with a stopcock at the bottom. Details about each installation and sampling protocol are described below.

\section{Meteor}

On the Meteor, the Palmex RS1 rain sampler was installed in a relatively unshielded location on the aft, starboard

335 railing of the navigation deck at $\sim 17.5$ m.a.s.l.. The location was chosen to limit the effects of wind interactions with the ship and so as to avoid obstruction of the area above the sampler by the main mast. The sampler funnel was cleaned regularly. Immediately after rainfall ended, samples were transferred to $2 \mathrm{~mL}$ vials, which were filled to minimize headspace and sealed with parafilm. Samples were stored in a refrigerator at $\sim 4^{\circ} \mathrm{C}$ during the cruise and again following shipment to the University of New Mexico Center for Stable Isotopes. Rainfall amount was

340 estimated by sample volume, however, an undercatch of around half was typical compared to the German Weather Service (DWD) rain gauge, designed for ship use, located on the mast. In total 15 rain samples, representing 15 separate rain events, were collected on the Meteor from 20 January to 19 February (DOY 20-50).

\section{Brown}

The Brown's custom rainwater sampler - composed of a large funnel attached to a conical separatory funnel with a stopcock at the bottom - was affixed to the railing on the O3 deck, the third deck above the main deck, off the starboard bow. The sampler was cleaned daily to remove sea spray and salt accumulation on the inside walls of the sampler's large funnel. Following a rain event, rainwater was drained from the separatory funnel into $30 \mathrm{~mL}$ glass vials with PolyCone caps. The glass vials were further sealed with parafilm to prevent evaporation at ambient temperature prior to laboratory analysis. Sample volume was not measured; however, the optical rain gauge aboard the Brown provides an estimate of precipitation rate (Quinn et al., 2021). A total of 12 samples, collected on the 
Brown between 5 January and 11 February (DOY 5-42), were analyzed after the campaign. Brown rainfall collection times were delayed in some cases by up to several days following measurable precipitation.

\section{Atalante}

On the Atalante, the Palmex RS1 rain sampler was affixed to the railing of the upper deck (just below the bridge and on the side towards the prow). Rainwater amounts were not independently measured, but water height in the rain sampler was observed before collection. There were eight instances where rain was reported on the ship's log but no water was collected in the rain sampler, suggesting winds may have influenced the sampler's collection efficiency. Usually, rain was collected within an hour of the end of the precipitation event. A total of six physically reasonable samples were collected on the Atalante from 23 January to 18 February (DOY 23-49.

\section{Merian}

The Palmex RS1 rain sampler on the Merian was affixed to the railing on the "Peildeck" or upper deck of the ship and shielded on the starboard side by the ship's superstructure. Samples were stored at ambient temperature in 1.5 and $15 \mathrm{~mL}$ vials sealed with parafilm. Samples were not weighed because rainfall amount was measured directly by a vertically pointing micro rain radar on the ship (MRR; Stephan et al., 2021). Measurements from the radar were

365 also used to attribute an amount-weighted mean time for each sample, which was then used to identify the vessel's geographic location. Because no rainfall was detected by the radar during one collection period, no geographic location could be assigned. A total of 23 rain samples were collected on the Merian from 20 January to 19 February (DOY 20-50).

\subsubsection{Seawater isotopic samples}

\section{Meteor}

The Meteor collected seawater for isotopic analysis from a depth of $10 \mathrm{~m}$ using the ship's Conductivity, Temperature, and Depth (CTD) profiler. Samples were collected daily from the CTD cast closest to 1900 UTC. An intensive observation period sampling a full diurnal cycle every two hours was also collected from 10-11 February 2020 (DOY 41-42) while the Meteor was on station for 24 hours at the northern intersection of its meridional

375 transect with the HALO circle $\left(14.18^{\circ} \mathrm{N}, 57.24^{\circ} \mathrm{W}\right)$. Seawater samples were treated with $\mathrm{CuCl}$ to prevent isotopic alteration by biotic activity. All samples were then sealed in $2 \mathrm{~mL}$ vials without headspace and sealed in parafilm. Samples were stored in a refrigerator at $\sim 4^{\circ} \mathrm{C}$ during the cruise and again following shipment to the University of New Mexico Center for Stable Isotopes. A total of 28 daily and 12 diurnal seawater samples are available from the Meteor.

Brown

The Brown collected seawater samples by a number of methods. Forty-four samples were collected by CTD cast across 10 days of the cruise; they provide information over a variety of depths from individual locations. Thirteen surface samples were also collected by throwing a bucket overboard from the starboard bow. These samples were taken approximately every six hours, over the course of two 2-day periods, to examine diurnal variability. Finally, 69 flowthrough samples were collected from the main ship laboratory. All seawater collection bottles were conditioned by filling and emptying the bottles three times prior to water sampling. Samples were then stored the same as rainwater in $30 \mathrm{~mL}$ glass vials with PolyCone caps and covered with parafilm. 


\section{Atalante}

The Atalante collected seawater for isotopic analysis from CTD casts (taken at varying depths) and also from a faucet associated with the thermosalinograph measuring the ship's water intake at a depth of $5 \mathrm{~m}$. Together, these two sampling strategies yielded 114 samples over 27 days. Seawater samples were not sealed with parafilm, and they were also exposed to high temperatures in transit back to the laboratory - the possible effects of which are discussed in Sect. 3. The samples are part of a multidecadal analysis of water isotope research cruise data (waterisotopes-CISE-LOCEAN 2021).

\section{Data post-processing and uncertainties}

In this section, we provide a detailed report of any corrections, adjustments, or masks applied to the isotopic data and describe key uncertainties that may affect their quality or interpretation. We also describe any anomalous data points or sampling periods. For some measurements, estimates of deuterium excess and its uncertainty are provided alongside the oxygen and hydrogen isotope ratios in units permil. The water vapor datasets additionally contain estimates of the water vapor concentration. Unless otherwise specified, these are given as mole fractions relative to total (moist) air in ppmv. All isotopic data are normalized to the VSMOW-SLAP (Vienna Standard Mean Ocean Water - Standard Light Antarctic Precipitation; Craig, 1961; IAEA, 2017) scale. Vapor isotopic measurements are also corrected, as necessary, for known biases associated with low water vapor concentrations and/or for instrumental drift (Aemisegger et al., 2012; Bailey et al., 2015). Any post-processing of water vapor concentration is

405 also described.

\subsection{Post-processing and uncertainties for water vapor isotopic measurements}

\section{BCO (ground-based)}

Water vapor isotope data from both the CRDS and OA-ICOS systems at the BCO were normalized to the VSMOWSLAP scale following the IAEA's procedure (IAEA, 2017), using the two most enriched liquid standards introduced

410 daily during the in-field calibration checks (Supplemental Information). Only the most stable parts of each calibration check (10-to-30 minutes in length) were selected for normalization. A linear interpolation between calibration checks was also used to correct for the small instrumental drift detected. For the CRDS system, the drift was $(0.2 \pm 0.1) \%$ day ${ }^{-1}$ for $\delta^{18} \mathrm{O}$ and $(2.1 \pm 2) \%_{0}$ day $^{-1}$ for $\delta \mathrm{D}$ compared to an average precision of the calibration measurements of $0.2 \%$ for $\delta^{18} \mathrm{O}$ and $0.9 \%$ for $\delta \mathrm{D}$.

Because previous studies have shown that the accuracy of the CRDS analyzer's isotopic measurements are independent of water vapor concentration in the humidity range typical of Barbados' tropical environment (e.g. 20,000-28,000 ppmv; Aemisegger et al., 2012), no humidity-dependence correction was applied to either the CRDS or OA-ICOS data. A post-campaign laboratory test of the CRDS system, conducted using a bubbler system (cf.

420 Ellehoj et al., 2013), verified the validity of this choice. The test found root mean square differences between isotopic measurements at a reference humidity value $(20,000 \mathrm{ppmv})$ and measurements at seven higher humidities (spanning 20,000 to 35,000 ppmv) of just $0.1 \%, 0.4 \%$, and $1.0 \%$ or for $\delta^{18} \mathrm{O}, \delta \mathrm{D}$, and $d$, respectively. The total isotopic measurement uncertainty for the $\mathrm{BCO}$ data is thus based on error propagation from the normalization to VSMOW-SLAP and the drift correction only. Uncertainty estimates for the CRDS system are 1.0\%, 3.0\%o and

$4253.1 \%$ for $\delta^{18} \mathrm{O}, \delta \mathrm{D}$, and $d$, respectively. Equivalent uncertainty estimates for the OA-ICOS system are $0.41 \%$, $0.94 \%$, and $3.31 \%$.

An additional source of uncertainty for the OA-ICOS analyzer are large oscillations in $\delta^{18} \mathrm{O}$ - on the order of $1 \%$ that were observed during some periods of ambient sampling. While the cause of these oscillations has yet to be 
identified, the fact that they appear only in one isotope ratio and not the other suggests an intermittent problem with the internal spectroscopy. The effect of this oscillation is not included in the OA-ICOS analyzer's isotopic uncertainty estimates.

Water vapor concentrations were corrected for the CRDS system but not the OA-ICOS system. For the CRDS analyzer, an independent linear scaling was applied (Supplemental Information) to adjust for a high bias in the range 10,000 to $30,000 \mathrm{ppmv}$ - which was determined after the campaign using a dew point generator - and to simultaneously convert wet mole fractions $\left(\mathrm{n}_{\mathrm{wv}} / \mathrm{n}_{\mathrm{t}}\right)$ to dry mole fractions $\left(\mathrm{n}_{\mathrm{wv}} /\left[\mathrm{n}_{\mathrm{t}}-\mathrm{n}_{\mathrm{wv}}\right]\right)$. Given the known small drift of the CRDS system's humidity measurements ( $<50$ ppmv per month), the bias was assumed constant over the course of the EUREC ${ }^{4} \mathrm{~A}$ deployment. The uncertainty of the corrected CRDS humidity measurements is 223 ppmv 440 (dry mole fraction).

Masked (missing) data in either BCO water vapor isotopic dataset represent periods when daily calibration checks or instrument maintenance were performed. All variables have been averaged in 1 minute intervals.

\section{ATR (airborne)}

445 The post-processing procedure for the ATR water vapor isotope data closely follows the procedure presented and applied in previous experiments using the same instrument (Aemisegger et al., 2012; Sodemann et al., 2017; Thurnherr et al., 2020). Normalization to VSMOW-SLAP was performed using a linear regression based on three standards and 32 calibration points measured between 25 January and 13 February 2020 (DOY 25-44). Calibration measurements were made at a reference humidity of 20,000 ppmv and deemed of sufficient quality to correct the ambient data if at least 3 minutes within the 10-to-20 minute calibration period presented no significant drift and exhibited standard deviations less than $1 \%$ in $\delta^{18} \mathrm{O}$, less than $2 \%$ in $\delta \mathrm{D}$, and less than $3000 \mathrm{ppmv}$ in water vapor concentration. Because the measured drift between flight days $\left( \pm 0.5 \%\right.$ day ${ }^{-1}$ for $\delta^{18} \mathrm{O}$ and $\pm 1 \%$ day ${ }^{-1}$ for $\left.\delta \mathrm{D}\right)$ was of comparable amplitude or smaller than the calibration measurement uncertainty $\left(0.3 \%\right.$ for $\delta^{18} \mathrm{O}$ and $1.25 \%$ for $\left.\delta \mathrm{D}\right)$, no drift correction was made.

Three additional corrections were applied based on post-campaign analyses and calibrations performed in August 2020 and March 2021:

1) The analyzer's water vapor concentrations were corrected and converted from wet $\left(\mathrm{n}_{\mathrm{wv}} / \mathrm{n}_{\mathrm{t}}\right)$ to dry mole fractions $\left(\mathrm{n}_{\mathrm{wv}} /\left[\mathrm{n}_{\mathrm{t}}-\mathrm{n}_{\mathrm{wv}}\right]\right)$ by applying a linear regression determined using a dew point generator.

2) Isotopic biases associated with low water vapor concentrations $(<10,000 \mathrm{ppmv})$ were eliminated by applying a two dimensional fit that accounts for both the water vapor concentration and its isotopic composition (Fig. 6a; cf. Weng et al., 2020). At high flow rates and isotopic values exceeding -30\%o in $\delta^{18} \mathrm{O}$ and $-260 \%$ in $\delta \mathrm{D}$, these biases were found to depend only on the water concentration and not on the isotope ratio (Thurnherr et al., 2020). The biases were quantified using three liquid standards, which were converted to gas phase and delivered to the CRDS analyzer in distinct concentrations using a custom-built bubbler system similar to that described in Steen-Larsen et al. (2014) (Fig. S3).

3) The isotopic and water vapor concentration time series were shifted to account for time delays in the airborne measurements. A time shift of $15 \mathrm{~s}$ - which was determined by lag-correlating the humidity measurements from the isotopic analyzer with those from the plane's dew point hygrometer - was applied to both isotope ratios and the water vapor concentration. The $\delta \mathrm{D}$ time series was further shifted by an additional $5 \mathrm{~s}$ to account for the higher adsorption tendency of the HDO molecule on tubing surfaces, which causes a slower time response (Aemisegger et al., 2012). Shifting the $\delta \mathrm{D}$ time series in this manner produced a maximum correlation of 0.995 with $\delta^{18} \mathrm{O}$.

Further details about the ATR calibration measurements and corrections, as well as a schematic of the custom-built 
At water vapor concentrations of 25,000 ppmv (which represent near-surface conditions near Barbados), total uncertainties in the ATR isotopic measurements are $0.8 \%, 1.7 \%$, and $1.9 \%$ for $\delta^{18} \mathrm{O}, \delta \mathrm{D}$, and $d$, respectively. Isotopic uncertainties increase as water vapor concentrations decrease but do not appear to depend on the isotopic composition of the vapor (Fig. 6b). Measurements of suspect quality, including those influenced by inlet wetting, are noted in the YAML files that accompany the dataset. See Bony et al. (2021) for a general description of these.

\section{P-3 (airborne)}

The P-3 water vapor isotope data were tested for dependencies on water vapor concentration both before and after the campaign. Based on these tests and the large uncertainties in measurement accuracy at low water vapor concentrations, no humidity-dependence correction was applied. Higher-than-expected uncertainties in the in-field calibration checks also precluded the detection of any instrumental drift. Therefore, only a simple linear transformation - based on a single post-campaign calibration - was used to normalize the data to the VSMOWSLAP scale (Supplemental Information).

490 To account for possible temporal variations in the analyzer's accuracy, maximal differences between correction functions derived in the field and those derived post-campaign were used to estimate uncertainties in the normalization (i.e. $\frac{1}{\sqrt{3}} \times$ max_difference). These normalization uncertainties were added in quadrature to the residual standard deviations from the humidity-dependence tests to derive total uncertainty estimates for the calibrated sample-rate isotope ratios. As shown in Fig. 7, the total uncertainty estimates (black lines) are of comparable 495 magnitude to the standard deviations of the $1 \mathrm{~Hz}$ isotopic averages derived from the sample-rate data (blue lines). Data users wishing to be extra conservative may consider adding these two representations of uncertainty (both provided in the data files) in quadrature (see Supplemental Information for further details).

Even with such extra precautions, reported uncertainties likely underestimate actual uncertainties at low water vapor concentrations for at least three reasons. First, the P-3 analyzer's normalization cannot be verified for isotopic values lower than the most depleted standard used. Second, despite finding no isotopic humidity dependence in laboratory tests conducted before and after the campaign, there is an obvious shifting bias in $\delta^{18} \mathrm{O}$ over the course of the field deployment. Figure 8 shows the effect of this transitory bias for research flight 8 , where positive $\delta^{18} \mathrm{O}$ values in the free troposphere are clearly unphysical. Finally, adsorption and mixing of water vapor within the aircraft sample line reduces isotopic accuracy by slowing the time response and weakening the signal of the isotopic measurements. These effects are much greater for $\delta \mathrm{D}$ compared to $\delta^{18} \mathrm{O}$ and are particularly evident in the low humidity conditions found at higher altitudes (Fig. 8).

Based on both quantifiable (Fig. 7) and unquantifiable (Fig. 8) measurement uncertainties, we recommend that

510 applications requiring a single isotope ratio use $\delta \mathrm{D}$ from the P-3; however, care should be taken at altitudes exceeding $5000 \mathrm{~m}$ (where hysteresis is most extreme) and at isotopic values below $-355 \%$ (where normalization cannot be verified). Moreover, although time periods when $\delta^{18} \mathrm{O}$ is clearly suspect have been marked with a qualitycontrol flag in the $1 \mathrm{~Hz}$ data, we do not recommend trusting estimates of $d$ in the free troposphere (above the boundary layer). Periods when both isotope ratios are masked (missing) reflect periods when the analyzer sampled

515 from the dew point generator or when the aircraft was taking off.

No time adjustment has been applied to the P-3 isotopic data to account for delays associated with the flow rate through the sample line. Instead, users are encouraged to apply the time correction described in Pincus et al. (2021) if desirable for their application. The correction for water vapor concentration is also described in Pincus et al. (2021) and in the Supplemental Information. 
The Meteor's isotopic observations were evaluated for their dependence on water vapor concentration shortly after the isotopic analyzer was installed on the ship. Gas generated from two liquid standards was measured across a range of eight humidities spanning 19,500 - 35,000 ppmv. Correction functions based on these tests were used to eliminate humidity-dependent biases in the research cruise data of up to $0.24 \%$ in $\delta^{18} \mathrm{O}$ and $0.36 \%$ in $\delta \mathrm{D}$.

To normalize the water vapor isotopic observations to the VSMOW-SLAP scale and correct for instrumental drift, measurements of the four standard waters run during the campaign were linearly interpolated to the observational sampling rate of $1 \mathrm{~Hz}$. Each ambient data point was then corrected using a unique linear model derived by fitting the interpolated measurements to the known standard values. In comparison, no correction was applied to the isotopic analyzer's humidity measurements. This decision was based on the fact that the isotopic analyzer's campaign-mean specific humidity value differed by only $0.13 \mathrm{~g} \mathrm{~kg}^{-1}$ from the ship's main meteorological station. The corrected isotope ratios and uncorrected humidity data were averaged to 1 minute.

535 Total uncertainties in the cruise measurements were estimated by summing in quadrature the bulk uncertainties associated with the liquid standards used to generate reference gas $\left(\delta^{18} \mathrm{O}, \delta \mathrm{D}=0.14 \%, 0.69 \%\right)$, the standard deviations of the residuals from the humidity-dependence correction $\left(\delta^{18} \mathrm{O}, \delta \mathrm{D}=0.10 \%, 0.32 \%\right.$ ), the average precision of the individual calibration measurement periods $\left(\delta^{18} \mathrm{O}, \delta \mathrm{D}=0.14 \%, 0.83 \% 0\right)$, and the variability in the mean measured calibration values over the course of the campaign $\left(\delta^{18} \mathrm{O}, \delta \mathrm{D}=0.18 \%\right.$, $0.50 \%$ ). Total uncertainties are thus estimated to be $0.29 \%$ for $\delta^{18} \mathrm{O}$ and $1.24 \%$ for $\delta \mathrm{D}$.

In addition to the isotopic corrections, observations have been masked (removed) during instrument maintenance or when sampling was not suitable for scientific purposes (e.g. when the wind fetch was influenced by the ship's smokestack). Data users should also be aware that precipitation and the subsequent evaporation of moisture from the ship's surfaces may have altered the water vapor isotopic measurements. Indeed, rain events coincided with some of the largest variations in vapor isotopic composition and also with some of the highest values of $\delta^{18} \mathrm{O}$ and $\delta \mathrm{D}$ observed by the Meteor (Fig. S4). A flag for periods with measured rainfall and the three hours following are included to assist with data interpretation.

\section{Brown (ship-based)}

550 Because the water vapor isotopic analyzer aboard the Brown sampled within a relatively high humidity range (17,500 pppmv - 28,300 ppmv), biases associated with water vapor concentration were assumed negligible, and no bias correction was applied. Only a linear scaling - based on the 26 January 2020 (DOY 26) calibration check - was used to normalize the data to the VSMOW-SLAP scale. Unfortunately, discrepancies in replicate laboratory measurements of the secondary standards used to calibrate the analyzer allow for a fairly large range of plausible normalization coefficients. The selected coefficients $\left(\beta_{0}=1.26 \%, \beta_{1}=0.98 \%\right.$ for $\delta^{18} \mathrm{O} ; \beta_{0}=5.89 \%$, $\beta_{1}=0.97 \%$ for $\delta \mathrm{D})$ are based on the average laboratory results. However, coefficients as different as $\left\{\beta_{0}=0.87 \%, \beta_{1}=0.96 \%\right.$ $\}$ and $\left\{\beta_{0}=1.85 \%, \beta_{1}=1.01 \% 0\right\}$ for $\delta^{18} \mathrm{O}$ and $\left\{\beta_{0}=4.96 \%\right.$, $\beta_{1}=0.96 \%$ o $\}$ and $\left\{\beta_{0}=6.60 \%, \beta_{1}=0.97 \%\right.$ o $\}$ for $\delta \mathrm{D}$ are also justifiable. Uncertainties in the Brown normalization are thus estimated as $\frac{1}{\sqrt{3}} \times$ max_difference, where max_difference is the maximal difference between plausible normalization curves for the range of isotope ratios measured near Barbados.

For the sample-rate measurements, the estimated normalization uncertainties are $1.15 \%$ for $\delta^{18} \mathrm{O}$ and $0.89 \%$ for $\delta \mathrm{D}$. These uncertainties are reduced when the data are averaged to 1 minute but by less than expected for an instrument with nominal $5 \mathrm{~Hz}$ sampling frequency. Because of strong lag 1 autocorrelation in the time series of both isotope ratios $\left(r=0.80\right.$ for $\delta^{18} \mathrm{O}, 0.83$ for $\left.\delta \mathrm{D}\right)$, the effective degrees of freedom are closer to 34 and 29 (rather than 308), 
which results in calibration-related uncertainty estimates of $0.20 \%$ and $0.17 \%$ for the 1 minute averages of $\delta^{18} \mathrm{O}$ and $\delta \mathrm{D}$, respectively. The standard deviations associated with the 1 minute averages are typically higher - and thus may be a preferred estimate of measurement uncertainty - likely because they also reflect variability in the environment.

570

Because the water vapor concentrations from the Brown analyzer were not calibrated before deployment, they are reported as measured. However, a comparison in 1 minute intervals with the ship's primary specific humidity measurement (qair; Quinn et al., 2021) suggests a median difference of just $0.20 \mathrm{~g} / \mathrm{kg}$ for all periods when the ship's contamination flag is 0 . This is equivalent to a potential positive bias of $320 \mathrm{ppmv}$ in water vapor mole fraction. Additional humidity comparisons between the isotopic analyzer's humidity measurements and the $10 \mathrm{~Hz}$ LiCOR on the ship (C. Fairall and E. Thompson, personal communication, 2020) were used to shift the isotopic analyzer's time series (following the formula $69.94-2.51 \times 10^{-5} t$ ) to address a drifting offset of 13.8 to -18.5 seconds over the course of the campaign.

Optimal sampling periods occurred when the Brown was pointed into the wind, minimizing contamination by the ship's stack aft of the aerosol container in which the analyzer was housed. The 1 minute isotopic data files contain a contamination flag equivalent to that found in the Brown meteorological data set, where a non-zero value marks periods of potential contamination (Quinn et al., 2021). A flag value of 2 has been added to the isotopic files to mark time periods when the Brown was near port, when other meteorological data are not reported. An additional flag has been added to mark periods when the blower, pulling air through the sampling mast, into the aerosol container, was reversed.

\section{Atalante (ship-based)}

Atalante water vapor isotopic measurements were corrected for dependencies on water vapor concentration, which were checked both before and after the cruise using a single isotopic standard. They were also normalized to VSMOW-SLAP by means of a simple linear regression, which was determined after the campaign using three liquid standards to generate reference gas. The effects of instrumental drift during the cruise were addressed by linearly interpolating the liquid standard measured daily to each ambient observation and subtracting the differences between the interpolated and known values. Three anomalous measurements were ignored in this procedure - those made on the 26, 29, and 30 January 2020 (DOY 26, 29, 30) - which may have been affected by shifts in the liquid standards themselves. However, since shifts in the instrument's spectroscopy cannot be ruled out, it is possible that the time series for the period 26 to 30 January 2020 (DOY 26-30) could be in error by approximately $0.4 \%$ in $\delta^{18} \mathrm{O}$ and $1.7 \%$ in $\delta \mathrm{D}$. An additional $0.6 \%$ offset was added to $\delta \mathrm{D}$ based on a suspected issue with the standard values. The isotopic data, once corrected, were averaged in 2 minute intervals.

600 Standard deviations associated with the 2 minute averages provide estimates of uncertainty for both the water vapor concentration and its isotopic composition; however, as with other platforms, actual uncertainties may be larger. Because in-field calibration checks relied on a single standard - one that was more depleted than the typical ambient vapor sampled - biases in the Atalante isotope ratios may be underestimated. In addition, questions remain about the representativeness of the water vapor sampled. Although the analyzer's inlet was positioned away from any vent on the ship, air from the ship's interior could have influenced the isotopic measurements at times. It is also not clear from which altitude air entering the analyzer would have originated and whether this would have depended on the direction of the wind relative to the ship. A comparison of the isotopic analyzer's water vapor concentrations with the ship's main meteorological station, however, suggests satisfactory agreement and allays some of these concerns. The CRDS water vapor data have been scaled by $2 \%$ based on this comparison.

Masked (missing) measurements in the Atalante vapor isotopic dataset include times during which the analyzer sampled reference gas and the period 0037 to 2212 UTC on 26 January (DOY 26), during which time the analyzer 
was not functioning properly. Poor data quality periods have been flagged, as have periods when the water vapor isotopic measurements were likely influenced by precipitation or by exhaust or recycled air from the ship.

\subsection{Uncertainties for rain and seawater samples}

Rain and seawater samples were analyzed in established isotopic laboratories following the EUREC ${ }^{4} \mathrm{~A}$ deployment. Rainwater isotope ratios for the BCO, Atalante, and Merian were measured with a Picarro L2130-i at the isotope laboratory at the University of Freiburg. Atalante seawater isotope ratios were analyzed at the LCISE facility of OSU Ecce Terra in France. And, rain and seawater isotope ratios from the Meteor and Brown were measured on a Picarro L2140-i at the University of New Mexico's Center for Stable Isotopes. (Analysis of Brown seawater samples is still ongoing.) Uncertainties reported in Table 1 are thus the analytical uncertainties associated with the long-term accuracy of the liquid standards used to determine the isotope ratios of each sample. Additional (unquantified) uncertainties may stem from small-scale variability in rainfall intensity and isotopic composition, as well as potential post-sampling evaporation. One study of 10 European precipitation events, using an array of samplers similar to the Palmex RS1, found such sampling uncertainties to be $<0.3 \%$ in $\delta 18 \mathrm{O}$ and $<2 \%$ in $\delta \mathrm{D}$ (Fischer et al., 2019).

That said, post-sampling evaporation may be of particular concern for samples from the Brown and for a selection of BCO rainwater and Atalante seawater samples. Several rainwater samples from the Brown were not collected until as much as a few days after rain had ended. Moreover, some samples may include catch from multiple storms, making it hard to gauge exactly how long rainwater remained in the sampler. For samples where it is known that collection was delayed for more than seven hours, flags are provided in the data file; however, all samples should be treated cautiously. Liquid samples from the Brown also remained in storage, without temperature regulation, in the ship's aerosol container for over a year due to access and shipping complications associated with the COVID-19 pandemic.

For the BCO, post-depositional evaporation may have also influenced the rainwater samples prior to collection. Although every attempt was made to collect rain samples immediately after precipitation, some samples remained in the sampler for one hour or more. A comparison of the measured isotope ratios with those predicted, assuming the

640 rainwater were in equilibrium with the ambient vapor, suggests that samples with longer collection delays are more enriched, relative to equilibrium, than the other samples. The BCO rainwater isotopic dataset includes a flag to identify samples potentially affected by evaporative enrichment.

Finally, of the 114 seawater samples analyzed from the Atalante, 23 have been flagged for potential post-sampling evaporation. It is believed that these samples "breathed" through leaky caps during storage in high temperature conditions at the port of Pointe à Pitre, where they remained for two months. These samples were corrected using an empirical relationship between $d$ and salinity that was based on previous sampling in the trade wind region. Higherthan-expected $d$ was then used to bias-correct $\delta^{18} \mathrm{O}$ and $\delta \mathrm{D}$, by assuming a 1:2 relationship between the two isotope ratios. Consequently, uncertainties in the isotopic estimates for these samples may be as large as $0.1 \%$ and $0.15 \%$ o

650 for $\delta^{18} \mathrm{O}$ and $\delta \mathrm{D}$, respectively.

\section{Cross-platform data comparisons and opportunities}

EUREC ${ }^{4} \mathrm{~A}^{\prime}$ 's extensive isotopic measurement network provides ample opportunity to examine spatiotemporal variability in the hydroclimate of the trade wind environment, as well as to assess the isotopic data quality more thoroughly. Here, we compare isotopic measurements across platforms, including between in situ and satellite-based sensors, in order to further evaluate estimates of measurement uncertainty. We also describe additional opportunities 
for isotopic data comparisons for future study. For information about other meteorological information collected during the field campaign period, readers are referred to the EUREC ${ }^{4}$ A special issue in Earth System Science Data.

\subsection{In situ isotopic data comparisons}

\subsubsection{Surface water vapor, rain, and seawater}

660 Campaign-mean values of isotope ratios in near-surface water vapor, rain, and seawater suggest broad coherence across platforms while also highlighting issues of potential concern. The water vapor values exhibit a subtle depletion - most evident in $\delta^{18} \mathrm{O}$ - from the southernmost latitudes (the Atalante) north to Tradewind Alley (the Meteor and Brown) and up to the aircraft legs at $150 \pm 15 \mathrm{~m}$ (ATR and P-3) (Fig. 9). These patterns are consistent with the widely accepted idea that isotope ratios tend to decrease with latitude and altitude, lending confidence to the measurement accuracy. A similar (though, again, very subtle) latitudinal pattern appears in the rain and seawater samples: the Meteor, Brown, and Merian being slightly more depleted than the more southerly Atalante, though all are quite close in value. Importantly, the strong cross-platform coherence in rainwater relies on carefully screening the data. Had Fig. 9 included samples flagged for late collection times, average rainwater isotope ratios from both the $\mathrm{BCO}$ and Brown would be higher. For the Brown, the difference is quite large: campaign-mean $\delta^{18} \mathrm{O}$ would

670 increase from -0.13 to $+0.61 \%$ while $\delta \mathrm{D}$ would increase from 10.68 to $13.36 \%$. Delayed collections also explain why the samples taken from aboard the Brown on 24 January (DOY 24) are more than 2.7 and 12.5\% more enriched in $\delta^{18} \mathrm{O}$ and $\delta \mathrm{D}$, respectively, than the BCO sample collected $20 \mathrm{nmi}$ downwind on the same day (Quinn et al., 2021). The Brown samples from the $24^{\text {th }}$ likely include both fresh precipitation from that day and old precipitation that had undergone evaporation while sitting in the collector.

Isotopic averages from the land surface are somewhat less consistent than those from the oceanic environment. While mean BCO rainwater, P-3 water vapor from the airport (approximately $14 \mathrm{~km}$ to the southwest of BCO), and water vapor from the BCO's OA-ICOS analyzer are more depleted than equivalent measurements at sea, water vapor from the BCO's CRDS analyzer is substantially more enriched. Surprisingly, the BCO's two analyzers are 1.5 and $4.5 \%$ different in $\delta^{18} \mathrm{O}$ and $\delta \mathrm{D}$, respectively, even though they sampled from the same inlet and were calibrated using the same standards and procedure. This unexpected discrepancy highlights the challenge of accurately estimating biases and uncertainties in water vapor isotopic field measurements using typical calibration approaches and suggests it may be necessary to measure a larger number of standards or to measure the standards for longer periods while in the field.

Despite their sizable mean offsets, time series from the two BCO analyzers are strongly correlated for both water vapor concentration and $\delta \mathrm{D}$, bolstering our confidence in the variability captured in their respective signals (Fig. 11, Table 2). (Correlation between the $\delta^{18} \mathrm{O}$ time series is diminished by the oscillation in the OA-ICOS signal but can be increased by applying a low pass filter or averaging to longer time steps.) Similar low-frequency coherence is

690 apparent when comparing the time series from the BCO with those measured by nearby ships. The Meteor, for example, was frequently close enough to Barbados' eastern shores that air masses sampled on the ship would have reached the BCO about 9 hours later (assuming easterly wind speeds of about $7 \mathrm{~m} \mathrm{~s}^{-1}$ ). Shifting the Meteor time series to account for this presumed time difference produces correlations with the CRDS analyzer of 0.4-to-0.5 when the datasets are averaged to 1 hour intervals. Spikes that appear in the Meteor time series but not the land-based datasets represent measurement periods affected by rainfall and subsequent evaporation from the ship's surfaces (previously described in Sect. 3.1; see Fig. S4).

\subsubsection{Atmospheric vertical profiles}

The two airborne isotopic analyzers provide an opportunity to evaluate 3-D isotopic variability in the tropical atmosphere. Ignoring the unphysically high free tropospheric $\delta^{18} \mathrm{O}$ from the P-3 (Sect. 3.1), both analyzers show the 
700 expected tendency toward isotopic depletion with height. Yet, there are some notable differences aloft. On average, lower free tropospheric $\delta$ D (approximately 2000-5000 m.a.s.1.) tends to be more depleted on the P-3 compared to the ATR. Arguably, some of this difference is due to the fact that the P-3 experienced a wider range of humidity conditions aloft, having sampled more extensively at higher altitude and across a wider longitudinal range. Supporting this idea is the fact that P-3 takeoffs and landings, which were flown in closest proximity to the HALO circle, are more similar in vertical structure to the ATR than the slantwise ascents and descents and cloud legs flown farther to the east (Fig. 12). (Differences between the takeoffs and landings reflect temporal variations in the humidity structure of the atmosphere).

That said, we suspect P-3 $\delta$ D may be biased low. For the earliest research flights, when P-3 $\delta^{18} \mathrm{O}$ was more trustworthy at altitude, the lowest $\delta^{18} \mathrm{O}$ values observed are consistent with the amount of distillation an air parcel from the local marine boundary layer would have experienced had it ascended pseudoadiabatically. In contrast, the $\delta \mathrm{D}$ values are substantially lower than the pseudoadiabatic (i.e. Rayleigh) prediction (not shown). Scientific investigations might thus consider scaling the P-3 $\delta \mathrm{D}$ to account for this inconsistency between the analyzer's two isotope ratios.

Estimates of the marine boundary layer isotopic composition - necessary for theoretical predictions of vertical isotopic change - can be derived not only from the airplanes themselves, but also from the other platforms, either by using the campaign-mean values or observations taken during targeted flyovers. The Meteor and Brown, for example, frequently probed the near-surface oceanic environment over which the ATR and P-3, respectively, flew. Quinn et al. (2021) provide a detailed list of periods during which the Brown was stationed within the P-3 dropsonde circle. Following each circle, the P-3 typically flew a slantwise descent, designed to sample the water vapor isotope ratio profile in the same geographic vicinity. The ATR also conducted targeted flyovers of the BCO and flew nearsurface legs, $60 \mathrm{~m}$ above the ocean surface, within the HALO circle (Bony et al., 2021).

\subsection{Remotely sensed and in situ isotopic data comparisons}

725 While EUREC ${ }^{4}$ A's in situ isotopic measurement network affords numerous opportunities to assess spatial variability in the trade wind environment, routine satellite retrievals of $\delta \mathrm{D}$ over the study region provide additional large-scale context for the in situ collections, as well as compositional information about air masses upstream of the target measurement region. Three satellite $\delta \mathrm{D}$ products are available for the EUREC ${ }^{4} \mathrm{~A}$ measurement region and time period as of this writing. NASA's Atmospheric Infrared Sounder (AIRS), aboard the Aqua satellite, provides an

730 estimate of mid-free tropospheric $\delta \mathrm{D}$, with greatest sensitivity to pressure altitudes between $825-400 \mathrm{hPa}$ (Worden et al., 2019; J. Worden, personal communication, 2020). The European Organisation for the Exploitation of Meteorological Satellites' (EUMETSAT) Infrared Atmospheric Sounding Interferometer (IASI; whose data collectively come from three satellites: Metop-A, Metop-B and Metop-C) provides estimates of mid-tropospheric $\delta \mathrm{D}$ (Schneider and Hase, 2011). And, the European Space Agency's (ESA) TROPOspheric Monitoring Instrument

735 (TROPOMI), onboard the Copernicus Sentinel-5 Precursor (S5P) satellite, provides an estimate of total-column $\delta \mathrm{D}$ (A. Schneider et al., 2021). Total-column isotopic retrievals are dominated by the lowermost altitudes, where most water vapor resides. All three remote sensors also provide retrievals of water vapor concentration.

The two European isotopic products have been repackaged into custom subsets for the EUREC ${ }^{4} \mathrm{~A}$-iso effort. One subset provides retrievals within a $10^{\circ} \times 10^{\circ}$ box defined by $5^{\circ}-15^{\circ} \mathrm{N}$ and $50^{\circ}-60^{\circ} \mathrm{W}$. The other covers an extended region to support Lagrangian analyses of air mass transport history (i.e. $21^{\circ} \mathrm{S}-54^{\circ} \mathrm{N}$ and $110^{\circ} \mathrm{W}-22^{\circ} \mathrm{E}$; see Villiger et al., 2021a). Both subsets cover the period between 10 January and 20 February 2020 (DOY 10-51).

The IASI dataset (generated by the latest version of the MUSICA retrieval algorithm; M. Schneider et al., 2021) is 
observations. These data are provided with full information for each individual observation (a priori profiles, averaging kernels, uncertainty covariances, etc.). In comparison, to reduce data volume and storage needs, $\mathrm{H}_{2} \mathrm{O}-\delta \mathrm{D}$ pairs for the extended EUREC ${ }^{4} \mathrm{~A}$-iso region are provided without full averaging kernels and only for three selected altitudes with high sensitivity: $2.9 \mathrm{~km}, 4.2 \mathrm{~km}$, and $6.4 \mathrm{~km}$. For both subsets, data are provided over land and ocean but only for cloud-free conditions. Typical uncertainties are $10-30 \%$ in $\delta \mathrm{D}$. Data users are referred to M. Schneider et al. (2021) and Diekmann et al. (2021c) for additional information (including the data user guide). The full MUSICA IASI $\mathrm{H}_{2} \mathrm{O}-\delta \mathrm{D}$ pair dataset can be accessed at https://dx.doi.org/10.35097/415.

TROPOMI's repackaged data contain the following variables for the extended EUREC ${ }^{4} \mathrm{~A}$-iso region: modified Julian date, longitude, latitude, column- $\mathrm{H}_{2} \mathrm{O}$ and - $\mathrm{HDO}$ with their retrieval errors, averaging kernels and a priori profiles, a posteriori column- $\delta \mathrm{D}$ and its retrieval error, and a quality flag. The quality flag is 1 for clear-sky scenes, 0.5 for scenes with low clouds (with co-retrieved cloud center height $2 \mathrm{~km}$ or less), and 0 for all other scenes. Data with a quality value of 0 should not be used. The median bias - relative to co-located ground-based Fourier transform infrared (FTIR) observations by the Total Carbon Column Observing Network (TCCON) - is $3 \%$ in $\mathrm{H}_{2} \mathrm{O}$ and $17 \%$ in $\delta \mathrm{D}$ for clear-sky scenes and $11 \%$ in $\mathrm{H}_{2} \mathrm{O}$ and $20 \%$ in $\delta \mathrm{D}$ for cloudy scenes. A. Schneider et al. (2021) describe the retrieval and provide a validation. The full TROPOMI data set is available from https://tropomi.grid.surfsara.nl/hdo/.

765 As demonstrated in Fig. 13, the satellites provide rich spatial context for the in situ data. Nevertheless, when using the two in tandem, care must be taken to consider differences in what each type of measurement represents. For example, even though TROPOMI's total column estimates are weighted toward the boundary layer, the TROPOMI $\delta \mathrm{D}$ values do not increase toward the equator (Fig. 13a) like the near-surface in situ values (Fig. 9). Instead, they vary with the atmosphere's vertical humidity structure, which alters the retrievals' sensitivity to low isotope ratios

770 aloft. Near Barbados, very depleted free tropospheric $\delta \mathrm{D}$ values have little influence on the total column retrieval since free tropospheric water vapor concentrations are so low (Fig. 13b). In contrast, in regions where deep convection regularly moistens the free troposphere, isotope ratios aloft have more influence in lowering the total column $\delta \mathrm{D}$.

775 Other important differences between the remotely sensed and in situ measurements emerge when comparing vertical profiles of water vapor and its isotopic composition from IASI, the P-3, and ATR. While IASI detects broad differences in vertical structure between the trade wind region and areas equatorward, it misses much of the finescale variability captured by the airborne sensors (Fig. 14; cf. Stevens et al., 2017). This smoothing is the result of IASI's wide averaging kernel, which causes measurements at any one pressure altitude to depend strongly on the

780 atmospheric state at numerous other levels. The effect is particularly evident in the boundary layer, where the remote sensor underpredicts $\delta \mathrm{D}$ due to its higher measurement sensitivity to the free troposphere. In contrast, despite resolving greater variability in the vertical, the aircraft measurements strongly convolve horizontal with vertical information (largely because of the way in which EUREC ${ }^{4} \mathrm{~A}$ flight patterns were designed). Moreover, each aircraft flight provides but a few distinct snapshots of the atmosphere's isotopic vertical structure, compared to the larger number of satellite retrievals within a given region.

Direct comparisons between the airborne and space-based measurements should therefore consider carefully how best to aggregate the data in space and time. For the most accurate comparison, the best practice is to apply the satellite instrument's averaging kernels to the in situ $\mathrm{H}_{2} \mathrm{O}$ and HDO profiles individually and then recalculate $\delta \mathrm{D}$ 790 from the smoothed airborne data. This avoids errors in the comparison caused by the imperfect vertical sensitivity of the satellite retrievals. 


\section{Data availability}

All EUREC ${ }^{4} \mathrm{~A}$ in situ water isotopic data and the repackaged IASI and TROPOMI products are available through the AERIS portal (https://eurec4a.aeris-data.fr/). Data from the P-3 and Brown are also archived at the National

795 Centers for Environmental Information (https://www.ncei.noaa.gov/). Individual datasets, which have been created for each platform and sample type (e.g. water vapor, precipitation, seawater), are listed in Table 3.

\section{Concluding perspective on dataset uses}

The collection of water vapor, rainwater, and seawater isotopic data gathered during EUREC ${ }^{4} \mathrm{~A}$ comprises one of the most extensive cross-platform water isotopic datasets to date. As a result, analyses using datasets specific to many of EUREC ${ }^{4} \mathrm{~A}$ 's airborne and ship-based platforms - as well as the $\mathrm{BCO}$ - will benefit from the extra observational constraint on water cycle processes that water isotopes provide. For instance, combining microphysical data, such as raindrop size distributions, with precipitation isotopic measurements could provide a novel way to independently verify rain evaporation rates (cf. Salamalakis et al., 2016; Graf et al., 2019). Similarly, comparing water isotopic information with moisture flux estimates - derived from eddy covariance or budget techniques - could provide complementary time-integrated and instantaneous perspectives on moisture exchange between the ocean and air or between distinct atmospheric layers. Water vapor isotope ratios could also constrain mixing processes, such as entrainment into the subcloud layer, and provide important context for interpreting anomalies in other atmospheric constituents (trace gases, aerosols) by helping identify the source regions and moisture transport pathways of distinct air masses.

The fact that the EUREC ${ }^{4} \mathrm{~A}$ dataset includes isotopic information for different moisture reservoirs also creates opportunities to evaluate scientific questions that have long interested water isotope researchers. For example, because the tropical marine boundary layer feeds the global water cycle, several recent studies have asked what controls the isotopic composition of this important near-surface layer (Benetti et al., 2018; Risi et al., 2020). These

815 studies have shown that the near-surface atmosphere is more depleted in isotopically heavy moisture than the often used "closure" assumption suggests. Devised by Merlivat and Jouzel (1979), the "closure" assumption explains variations in marine boundary layer isotope ratios solely in terms of local thermodynamic conditions and evaporation, neglecting the potential influence of entrainment of dry air from the free troposphere above. However, the relatively high isotope ratios it predicts match neither data collected during previous ocean cruises (Benetti et al., 2014; 2018) nor Large-Eddy Simulations (LES; Risi et al., 2020). Testing of alternative frameworks that do account for free tropospheric entrainment has been hampered by a lack of co-located oceanic, near-surface water vapor, and lower free tropospheric water vapor isotopic data (cf. Benetti et al., 2018). EUREC ${ }^{4}$ 's isotopic measurements of seawater, near-surface water vapor from ships, and atmospheric profiles from aircraft provide a unique opportunity to test such frameworks over highly resolved spatial and temporal scales. Moreover, the improved understanding of

825 water, energy, and mass budgets in the sub-cloud layer afforded by EUREC ${ }^{4} \mathrm{~A}^{\prime}$ s many meteorological and oceanographic observations will no doubt help refine estimates of the equivalent water isotopic budget.

The distribution of isotopic measurement platforms across the EUREC ${ }^{4} \mathrm{~A}$ sampling region also lends itself to Lagrangian analyses aimed at studying variations in convective activity and cloudiness as air masses advect

830 westward with the trade winds. Isotope ratios can provide important additional constraints for such case studies, helping evaluate thermodynamic and microphysical controls on convective development. Typically, the P-3 and Brown sampled the eastern side of the EUREC ${ }^{4} \mathrm{~A}$ domain, while the ATR and Meteor sampled downwind and to the west. All of these platforms measured upwind of the BCO, potentially creating opportunities to track air masses for multiple hours, if not days, at a time. Such analyses could be especially useful for evaluating numerical simulations at the large-eddy scale. 
The EUREC ${ }^{4} \mathrm{~A}$ isotopic dataset could also prove useful for evaluating numerical simulations more broadly, such as has been done recently for the eastern subtropical North Atlantic (Diekmann et al., 2021a; Dahinden et al., 2021). Afterall, few water vapor datasets provide vertically resolved isotopic information. Moreover, the limited number of airborne isotopic measurements that existed prior to $\mathrm{EUREC}^{4} \mathrm{~A}$ primarily represent higher latitude regions (e.g. Ehhalt et al., 2005; He and Smith, 1999; Herman et al., 2014; Dryoff et al., 2015; Sodemann et al., 2017; Salmon et al., 2019). EUREC ${ }^{4}$ A greatly extends the current small body of observed isotopic profiles from the tropical lower troposphere (cf. Bailey et al., 2013; Herman et al., 2020). Similarly, the liquid water samples collected during EUREC $^{4} A$ help extend the spatial coverage of existing archives (e.g. Schotterer et al., 1996; Schmidt et al. 1999), providing critical observational checks for model climatologies.

All told, EUREC ${ }^{4} \mathrm{~A}$ facilitated the joint deployment of a number of unusual and experimental measurements to address outstanding questions related to convection and cloudiness in the shallow convective environment of the western Tropical Atlantic (Stevens et al., 2021). The seven in situ water vapor isotopic datasets, five precipitation isotopic datasets, and three seawater isotopic datasets described in this paper helped contribute to EUREC ${ }^{4} \mathrm{~A}$ 's bold approach and are openly available for the community to use in evaluating the processes that regulate the shallow convective hydroclimate state.

\section{Author contribution}

$\mathrm{AB}, \mathrm{FA}, \mathrm{LV}, \mathrm{SAL}, \mathrm{GR}$, and EQM coordinated measurements in the field, processed the data, and drafted the manuscript. SB, JG, DN, PKQ, SS, BS, and EJT designed and directed sampling strategies for the isotopic measurement network and individual platforms. CA, DBB, TB, DC, SPdS, MD, DH, PM, MR provided critical measurement support and guidance on data quality. TB, CJD, AS, and MS provided the remotely sensed data and their descriptions. All authors helped edit and refine the initial manuscript draft.

\section{Competing interests}

860 The authors declare that they have no conflict of interest.

\section{Acknowledgements}

The extensive measurements of water isotope ratios during EUREC ${ }^{4} \mathrm{~A}$ would not have been possible without the many operational and technical staff who supported each research facility, including (but not limited to) captains, pilots, other ship and aircraft crew, technicians, engineers, project managers and administrators. Specific support for seawater collections was provided by Alex de Klerk, Jérôme Demange, and Kyla Drushka. Several students also assisted with rainwater collections at BCO. We thank fellow chief scientists Chris Fairall, Janet Intrieri (leg 2 of Brown cruise), Johannes Karstensen, Stefan Kinne, and Wiebke Mohr for their leadership in planning and directing sampling from the various research vessels and aircraft, as well as Peter Blossey, whose vision helped guide the EUREC $^{4} \mathrm{~A}$-iso effort. We also thank our other scientific colleagues who joined us in the field and shared their expertise and enthusiasm. We are grateful to Eric DeWeaver and Brigitte Bauerle for facilitating a last-minute, midcampaign swap of isotopic analyzers on the Brown and to Vincent Douet and Tim Boyer for help with data archiving. We thank the CIMH and Marvin Forde (CIMH) for their help with logistics and customs in Barbados. We are also grateful to Friedhelm Jansen (MPI Hamburg) and Mario Mech (University of Cologne) for their very valuable support: from logistics on the island to help with instrument setups at the BCO. We thank Barbara

875 Herbstritt at the University of Freiburg im Breisgau for measuring the isotope composition of the BCO, Merian, and Atalante rain samples, the LCISE facility of OSU Ecce Terra in France for processing the Atalante seawater 
samples, and Nicu-Viorel Atudorei and his team at the University of New Mexico's Center for Stable Isotopes for analyzing the Brown and Meteor liquid samples.

880 Many funding programs supported the researchers and facilities involved in EUREC ${ }^{4}$ A-iso. F.A. and L.V were funded by Swiss National Science Foundation Grant No. 188731, S.L. and G.J. were supported by NSF ATM 1937583, E.Q.M. and S.P.d.S. were supported by NOAA Climate Variability and Predictability Program Award NA19OAR4310375, D.B.B. was supported by Poland's National Science Centre grant no.UMO-

2018/30/M/ST10/00674, M.D. was funded by NSF grant AGS-1938108, and D.H. and D.N. were supported by NSF

885 Climate and Large-Scale Dynamics Award 1937780. In addition, this material is based upon work supported by the National Center for Atmospheric Research, which is a major facility sponsored by the National Science Foundation under Cooperative Agreement 1852977. For D.C. and P.K.Q. this is PMEL contribution number 5324. This work is also a contribution to the LEFE/IMAGO-GMMC project EUREC ${ }^{4} \mathrm{~A}-\mathrm{OA}$, to the JPI-Climate and JPI Oceans project EUREC ${ }^{4} \mathrm{~A}-\mathrm{OA}$, and to the TOSCA SMOS-Ocean and EUREC ${ }^{4} \mathrm{~A}-\mathrm{OA}$ projects supported by CNES (Centre National

890 d'Études Spatiales). Support for these projects was also obtained from IFREMER, the French Research Fleet, the French Research Infrastructures AERIS and ODATIS, IPSL, the "Chaire Chanel" of the Geosciences Department at ENS and the European Union's Horizon 2020 research and innovation program under grant agreement no. 817578 TRIATLAS. The NOAA Climate Program Office, under the Climate Variability and Predictability Program, supported ATOMIC and the deployment of the P-3 and Brown. European Research Council (ERC) grant No 694768

895 (EUREC $\left.{ }^{4} \mathrm{~A}\right)$ funded the ATR operations.

We also thank those programs that supported the satellite data processing. TROPOMI data processing was carried out on the Dutch national E-infrastructure with the support of the SURF Cooperative. The MUSICA IASI retrievals were initiated during the project MUSICA (funded by the European Research Council under the European

900 Community's Seventh Framework Programme (FP7/2007-2013)/ERC Grant Agreement number 256961). The MUSICA IASI work received financial support through MOTIV and TEDDY (funded by the Deutsche Forschungsgemeinschaft under project IDs/Geschäftszeichen 290612604/GZ:SCHN1126/2-1 and 416767181/GZ:SCHN1126/5-1, respectively), and INMENSE (funded by the Ministerio de Economía y Competividad from Spain, CGL2016-80688-P). MUSICA IASI retrieval calculations were performed on the 905 supercomputers ForHLR and HoreKa, funded by the Ministry of Science, Research and the Arts BadenWürttemberg and by the German Federal Ministry of Education and Research. The MUSICA IASI work was also carried out with support from the Teide High-Performance Computing facilities, provided by the Instituto Tecnológico y de Energías Renovables (ITER), S.A (teidehpc.iter.es).

\section{References}

910 Aemisegger, F., Sturm, P., Graf, P., Sodemann, H., Pfahl, S., Knohl, A., and Wernli, H.: Measuring variations of $\delta 18 \mathrm{O}$ and $\delta 2 \mathrm{H}$ in atmospheric water vapour using two commercial laser-based spectrometers: an instrument characterisation study, Atmos. Meas. Tech., 5, 1491-1511, https://doi.org/10.5194/amt-5-1491-2012, 2012.

Aemisegger, F., Spiegel, J. K., Pfahl, S., Sodemann, H., Eugster, W., and Wernli, H.: Isotope meteorology of cold 915 front passages: A case study combining observations and modeling, Geophys. Res. Lett., 42, 5652- 5660, doi:10.1002/2015GL063988, 2015.

Aemisegger, F., Vogel, R., Graf, P., Dahinden, F., Villiger, L., Jansen, F., Bony, S., Stevens, B., and Wernli, H.: How Rossby wave breaking modulates the water cycle in the North Atlantic trade wind region, Weather Clim. Dynam., 2, 281-309, https://doi.org/10.5194/wcd-2-281-2021, 2021 a. 
Aemisegger, F., Dütsch, M., Rösch, M., and Villiger, L.: Calibrated stable water vapour isotope measurements on board the ATR-42 during EUREC4A [data set], Aeris. https://doi.org/10.25326/244, 2021b.

Bailey, A., Toohey, D., and Noone, D.: Characterizing moisture exchange between the Hawaiian convective boundary layer and free troposphere using stable isotopes in water, J. Geophys. Res., 118, 8208-8221, doi:10.1002/jgrd.50639, 2013.

Bailey, A., Noone, D., Berkelhammer, M., Steen-Larsen, H. C., and Sato, P.: The stability and calibration of water vapor isotope ratio measurements during long-term deployments, Atmos. Meas. Tech., 8, 4521-4538, doi:10.5194/amt-8-4521-2015, 2015.

Bailey, A., Henze, D., and Noone, D.: ATOMIC aircraft water vapor isotopic analyzer: Humidity and water vapor isotope ratios from aboard N43 aircraft in the North Atlantic Ocean, Barbados: Atlantic Tradewind Ocean-

935 Atmosphere Mesoscale Interaction Campaign 2020-01-17 to 2020-02-11 (NCEI Accession 0220631) [data set], NOAA National Centers for Environmental Information, https://doi.org/10.25921/c5yx-7w29, 2020.

Bailey, A. and Noone, D.: ATOMIC ship water vapor isotopic analyzer: Near-surface humidity and water vapor isotope ratios from aboard NOAA Ship Ronald H. Brown in the North Atlantic Ocean, near Barbados: Atlantic Tradewind Ocean-Atmosphere Mesoscale Interaction Campaign 2010-01-26 to 2020-02-10 (NCEI Accession 0225417) [data set], NOAA National Centers for Environmental Information, https://doi.org/10.25921/s76r-1n85, 2021.

Bates, T. S., Coffman, D. J., Covert, D. S., and Quinn, P. K., Regional marine boundary layer aerosol size distributions in the Indian, Atlantic, and Pacific Oceans: A comparison of INDOEX measurements with ACE-1, ACE-2, and Aerosols99, J. Geophys. Res., 107( D19), 8026, doi:10.1029/2001JD001174, 2002.

Benetti, M., Reverdin, G., Pierre, C., Merlivat, L., Risi, C., Steen-Larsen, H. C., and Vimeux, F.: Deuterium excess in marine water vapor: Dependency on relative humidity and surface wind speed during evaporation, J. Geophys. Res. Atmos, 119, 584-593, https://doi.org/10.1002/2013JD020535, 2014.

Benetti, M., Aloisi, G., Reverdin, G., Risi, C., and Sèze, G.: Importance of boundary layer mixing for the isotopic composition of surface vapor over the subtropical North Atlantic Ocean, J. Geophys. Res. Atmos., 120, 2190- 2209. doi: $10.1002 / 2014 J D 021947,2015$.

Benetti, M., Lacour, J.-L., Sveinbjörnsdóttir, A. E., Aloisi, G., Reverdin, G., Risi, C., Peters, A. J., and SteenLarsen, H. C.: A framework to study mixing processes in the marine boundary layer using water vapor isotope measurements Geophys. Res. Lett., 45, 2524-2532, https://doi.org/10.1002/2018GL077167, 2018.

Bony, S., Stevens, B., Ament, F. et al. : EUREC4A: A field campaign to elucidate the couplings between clouds, convection and circulation, Surv. Geophys., 38, 1529-1568, https://doi.org/10.1007/s10712-017-9428-0, 2017.

Bony, S. et al: ATR operations, instrumentations and measurements during EUREC4A, Earth Syst. Sci. Data, in preparation, 2021.

Brilouet, P.-E., Lothon, M., Etienne, J.-C., Richard, P., Bony, S., Lernoult, J., Bellec, H., Vergez, G., Perrin, T., Delanoë, J., Jiang, T., Pouvesle, F., Lainard, C., Cluzeau, M., Guiraud, L., Medina, P., and Charoy, T.: The EUREC4A turbulence dataset derived from the SAFIRE ATR 42 aircraft, Earth Syst. Sci. Data, 13, 3379-3398, https://doi.org/10.5194/essd-13-3379-2021, 2021. 
Chazette, P., Totems, J., Baron, A., Flamant, C., and Bony, S.: Trade-wind clouds and aerosols characterized by airborne horizontal lidar measurements during the EUREC4A field campaign, Earth Syst. Sci. Data, 12, 2919-2936, https://doi.org/10.5194/essd-12-2919-2020, 2020.

Craig, H.: Isotopic variations in meteoric waters, Science, 133, 1702-1703, https://doi.org/10.1126/science.133.3465.1702, 1961.

Dahinden, F., Aemisegger, F., Wernli, H., Schneider, M., Diekmann, C. J., Ertl, B., Knippertz, P., Werner, M., and Pfahl, S.: Disentangling different moisture transport pathways over the eastern subtropical North Atlantic using multi-platform isotope observations and high-resolution numerical modelling, Atmos. Chem. Phys., 21, 1631916347, https://doi.org/10.5194/acp-21-16319-2021, 2021.

Dansgaard, W.: Stable isotopes in precipitation, Tellus, 16, 436-468, https://doi.org/10.3402/tellusa.v16i4.8993, 1964.

985

Diekmann, C. J., Schneider, M., Knippertz, P., de Vries, A. J., Pfahl, S., Aemisegger, F., Dahinden, F., Ertl, B., Khosrawi, F., Wernli, H., and Braesicke, P.: 1. A Lagrangian perspective on stable water isotopes during the West African Monsoon. Journal of Geophysical Research: Atmospheres, 126, e2021JD034895.

https://doi.org/10.1029/2021JD034895, 2021a.

990

Diekmann, C., Schneider, M., and Ertl, B.: MUSICA IASI water isotopologue pair product (a posteriori processing version 2), customized subset for EUREC4A-iso [Data set], Aeris, https://doi.org/10.25326/262, 2021 b.

Diekmann, C. J., Schneider, M., Ertl, B., Hase, F., García, O., Khosrawi, F., Sepúlveda, E., Knippertz, P., and Braesicke, P.: The global and multi-annual MUSICA IASI $\{\mathrm{H} 2 \mathrm{O}, \delta \mathrm{D}\}$ pair dataset, Earth Syst. Sci. Data, 13, 52735292, https://doi.org/10.5194/essd-13-5273-2021, $2021 \mathrm{c}$.

Dyroff, C., Sanati, S., Christner, E., Zahn, A., Balzer, M., Bouquet, H., McManus, J. B., González-Ramos, Y., and Schneider, M.: Airborne in situ vertical profiling of HDO / H216O in the subtropical troposphere during the

1000 MUSICA remote sensing validation campaign, Atmos. Meas. Tech., 8, 2037-2049, https://doi.org/10.5194/amt-82037-2015, 2015.

Ehhalt, D. H., Rohrer, F., and Fried, A.: Vertical profiles of HDO/H2O in the troposphere, J. Geophys. Res., 110, D13301, doi:10.1029/2004JD005569, 2005.

1005

Fischer, B. M. C., Aemisegger, F., Graf, P., Sodemann, H., and Seibert, J.: Assessing the sampling quality of a lowtech low-budget volume-based rainfall sampler for stable isotope analysis, Front. Earth Sci., 7, 244, doi:10.3389/feart.2019.00244, 2019.

1010 Galewsky, J.: BCO LGR Water Vapor Isotopic Composition [data set], Aeris. https://doi.org/10.25326/309, 2020a.

Galewsky, J.: Level-1 Continuous In-situ Water Vapor Isotopic Composition [data set], Aeris. https://doi.org/10.25326/83, 2020b.

1015 Galewsky, J.: M161 Rainwater Isotopic Composition [data set], Aeris. https://doi.org/10.25326/308, 2020c.

Galewsky, J.: M161 Surface Seawater Isotopic Composition [data set], Aeris. https://doi.org/10.25326/307, 2020d. 

atmospheric water vapor and applications to the hydrologic cycle, Rev. Geophys., 54, 809- 865, doi:10.1002/2015RG000512, 2016.

Gat, J. R.: Oxygen and hydrogen isotopes in the hydrologic cycle, Ann. Rev. Earth Pl. Sc., 24, 225-262, https://doi.org/10.1146/annurev.earth.24.1.225, 1996.

1025

Graf, P., Wernli, H., Pfahl, S., and Sodemann, H.: A new interpretative framework for below-cloud effects on stable water isotopes in vapour and rain, Atmos. Chem. Phys., 19, 747-765, https://doi.org/10.5194/acp-19-747-2019, 2019.

1030 Gröning, M., Lutz, H.O., Roller-Lutz, Z., Kralik, M., Gourcy, L., and Pöltenstein, L.: A simple rain collector preventing water re-evaporation dedicated for $\delta 18 \mathrm{O}$ and $\delta 2 \mathrm{H}$ analysis of cumulative precipitation samples, J. Hydrol., 448-449, 195-200, https://doi.org/10.1016/j.jhydrol.2012.04.041, 2012.

He, H. and Smith, R. B.: Stable isotope composition of water vapor in the atmospheric boundary layer above the

1035 forests of New England, J. Geophys. Res., 104, 11657- 11673, doi:10.1029/1999JD900080, 1999.

Herman, R. L., Cherry, J. E., Young, J., Welker, J. M., Noone, D., Kulawik, S. S., and Worden, J.: Aircraft validation of Aura Tropospheric Emission Spectrometer retrievals of HDO / H2O, Atmos. Meas. Tech., 7, $3127-$ 3138, https://doi.org/10.5194/amt-7-3127-2014, 2014.

1040

Herman, R. L., Worden, J., Noone, D., Henze, D., Bowman, K., Cady-Pereira, K., Payne, V. H., Kulawik, S. S., and Fu, D.: Comparison of optimal estimation HDO/H2O retrievals from AIRS with ORACLES measurements, Atmos. Meas. Tech., 13, 1825-1834, https://doi.org/10.5194/amt-13-1825-2020, 2020.

1045 Hurley, J. V., Galewsky, J., Worden, J., and Noone, D.: A test of the advection-condensation model for subtropical water vapor using stable isotopologue observations from Mauna Loa Observatory, Hawaii, J. Geophys. Res., 117 , D19118, doi:10.1029/2012JD018029, 2012.

IAEA - International Atomic Energy Agency: Reference sheet for VSMOW2 and SLAP2 international

1050 measurement standards, IAEA, Vienna, 8 pp., 2017.

Konow, H., Ewald, F., George, G., Jacob, M., Klingebiel, M., Kölling, T., Luebke, A. E., Mieslinger, T., Pörtge, V., Radtke, J., Schäfer, M., Schulz, H., Vogel, R., Wirth, M., Bony, S., Crewell, S., Ehrlich, A., Forster, L., Giez, A., Gödde, F., Groß, S., Gutleben, M., Hagen, M., Hirsch, L., Jansen, F., Lang, T., Mayer, B., Mech, M., Prange, M., 1055 Schnitt, S., Vial, J., Walbröl, A., Wendisch, M., Wolf, K., Zinner, T., Zöger, M., Ament, F., and Stevens, B.: EUREC4A's HALO, Earth Syst. Sci. Data, 13, 5545-5563, https://doi.org/10.5194/essd-13-5545-2021, 2021.

Medeiros, B. and Nuijens, L.: Clouds at Barbados are representative of clouds across the trade wind regions in observations and climate models, PNAS, 113, 6102-6104, https://doi.org/10.1073/pnas.ss11322, 2016.

Merlivat, L. and Jouzel, J.: Global climatic interpretation of the deuterium-oxygen 18 relationship for precipitation, J. Geophys. Res., 84, 5029- 5033, doi:10.1029/JC084iC08p05029, 1979.

Noone, D., Galewsky, J., Sharp, Z. D., Worden, J., Barnes, J., Baer, D., Bailey, A., Brown, D. P., Christensen, L., 1065 Crosson, E., Dong, F., Hurley, J. V., Johnson, L. R., Strong, M., Toohey, D., Van Pelt, A., and Wright, J. S.: Properties of air mass mixing and humidity in the subtropics from measurements of the $\mathrm{D} / \mathrm{H}$ isotope ratio of water vapor at the Mauna Loa Observatory, J. Geophys. Res., 116, D22113, doi:10.1029/2011JD015773, 2011. 
Quiñones Meléndez, E., de Szoeke, S. P., and Noone, D.: Rainwater isotope ratios from samples taken aboard NOAA Ship Ronald H. Brown in the North Atlantic Ocean, near Barbados: Atlantic Tradewind Ocean-Atmosphere Mesoscale Interaction Campaign 2010-01-05 to 2020-02-11 [data set], NOAA National Centers for Environmental Information, https://doi.org/10.25921/bbje-6y41, in preparation, 2021.

Quinn, P. K., Thompson, E. J., Coffman, D. J., Baidar, S., Bariteau, L., Bates, T. S., Bigorre, S., Brewer, A., de 1075 Boer, G., de Szoeke, S. P., Drushka, K., Foltz, G. R., Intrieri, J., Iyer, S., Fairall, C. W., Gaston, C. J., Jansen, F., Johnson, J. E., Krüger, O. O., Marchbanks, R. D., Moran, K. P., Noone, D., Pezoa, S., Pincus, R., Plueddemann, A. J., Pöhlker, M. L., Pöschl, U., Quinones Melendez, E., Royer, H. M., Szczodrak, M., Thomson, J., Upchurch, L. M., Zhang, C., Zhang, D., and Zuidema, P.: Measurements from the RV Ronald H. Brown and related platforms as part of the Atlantic Tradewind Ocean-Atmosphere Mesoscale Interaction Campaign (ATOMIC), Earth Syst. Sci. Data,

1080 13, 1759-1790, https://doi.org/10.5194/essd-13-1759-2021, 2021.

Pincus, R., Fairall, C. W., Bailey, A., Chen, H., Chuang, P. Y., de Boer, G., Feingold, G., Henze, D., Kalen, Q. T., Kazil, J., Leandro, M., Lundry, A., Moran, K., Naeher, D. A., Noone, D., Patel, A. J., Pezoa, S., PopStefanija, I., Thompson, E. J., Warnecke, J., and Zuidema, P.: Observations from the NOAA P-3 aircraft during ATOMIC, Earth 1085 Syst. Sci. Data, 13, 3281-3296, https://doi.org/10.5194/essd-13-3281-2021, 2021.

Risi, C., Muller, C., and Blossey, P.: What controls the water vapor isotopic composition near the surface of tropical oceans? Results from an analytical model constrained by large-eddy simulations, J. Adv. Model. Earth Sy., 12, e2020MS002106, https://doi.org/10.1029/2020MS002106, 2020.

Salamalikis, V., Argiriou, A. A., and Dotsika, E.: Isotopic modeling of the sub-cloud evaporation effect in precipitation, Sci. Total Environ., 544, 1059-1072, https://doi.org/10.1016/j.scitotenv.2015.11.072, 2016.

Salmon, O. E., Welp, L. R., Baldwin, M. E., Hajny, K. D., Stirm, B. H., and Shepson, P. B.: Vertical profile observations of water vapor deuterium excess in the lower troposphere, Atmos. Chem. Phys., 19, 11525-11543, https://doi.org/10.5194/acp-19-11525-2019, 2019.

Schmidt, G.A., Bigg, G. R., and Rohling, E. J.: Global Seawater Oxygen-18 Database - v1.22 [data set], https://data.giss.nasa.gov/o18data/, 1999.

1100

Schneider, A. and Borsdorff, T.: TROPOMI total-column water vapor isotopologue pairs (a posteriori processing level 2b), customized subset for EUREC4A-iso [data set], Aeris, https://doi.org/10.25326/306, 2021.

Schneider, A., Borsdorff, T., aan de Brugh, J., Aemisegger, F., Feist, D. G., Kivi, R., Hase, F., Schneider, M., and

1105 Landgraf, J.: First data set of H2O/HDO columns from the Tropospheric Monitoring Instrument (TROPOMI), Atmos. Meas. Tech., 13, 85-100, https://doi.org/10.5194/amt-13-85-2020, 2020.

Schneider, A., Borsdorff, T., aan de Brugh, J., Lorente, A., Aemisegger, F., Noone, D., Henze, D., Kivi, R., and Landgraf, J.: Retrieving H2O/HDO columns over cloudy and clear-sky scenes from the Tropospheric Monitoring

1110 Instrument (TROPOMI), Atmos. Meas. Tech. Discuss. [preprint], https://doi.org/10.5194/amt-2021-141, in review, 2021.

Schneider, M. and Hase, F.: Optimal estimation of tropospheric H2O and $\delta$ D with IASI/METOP, Atmos. Chem. Phys., 11, 11207-11220, doi:10.5194/acp-11-11207-2011, 2011. 
Schneider, M., Ertl, B., Diekmann, C. J., Khosrawi, F., Weber, A., Hase, F., Höpfner, M., García, O. E., Sepúlveda, E., and Kinnison, D.: Design and description of the MUSICA IASI full retrieval product, Earth Syst. Sci. Data Discuss. [preprint], https://doi.org/10.5194/essd-2021-75, in review, 2021.

1120 Schotterer, U., Oldfield, F., and Froehlich, K.: GNIP Global Network for Isotopes in Precipitation, Laederach AG, Switzerland, 1996.

Sodemann, H., Aemisegger, F., Pfahl, S., Bitter, M., Corsmeier, U., Feuerle, T., Graf, P., Hankers, R., Hsiao, G., Schulz, H., Wieser, A., and Wernli, H.: The stable isotopic composition of water vapour above Corsica during the

1125 HyMeX SOP1 campaign: insight into vertical mixing processes from lower-tropospheric survey flights, Atmos. Chem. Phys., 17, 6125-6151, https://doi.org/10.5194/acp-17-6125-2017, 2017.

Steen-Larsen, H. C., Sveinbjörnsdottir, A. E., Peters, A. J., Masson-Delmotte, V., Guishard, M. P., Hsiao, G., Jouzel, J., Noone, D., Warren, J. K., and White, J. W. C.: Climatic controls on water vapor deuterium excess in the 1130 marine boundary layer of the North Atlantic based on 500 days of in situ, continuous measurements, Atmos. Chem. Phys., 14, 7741-7756, https://doi.org/10.5194/acp-14-7741-2014, 2014.

Stephan, C. C., Schnitt, S., Schulz, H., Bellenger, H., de Szoeke, S. P., Acquistapace, C., Baier, K., Dauhut, T., Laxenaire, R., Morfa-Avalos, Y., Person, R., Quiñones Meléndez, E., Bagheri, G., Böck, T., Daley, A., Güttler, J.,

1135 Helfer, K. C., Los, S. A., Neuberger, A., Röttenbacher, J., Raeke, A., Ringel, M., Ritschel, M., Sadoulet, P., Schirmacher, I., Stolla, M. K., Wright, E., Charpentier, B., Doerenbecher, A., Wilson, R., Jansen, F., Kinne, S., Reverdin, G., Speich, S., Bony, S., and Stevens, B.: Ship- and island-based atmospheric soundings from the 2020 EUREC4A field campaign, Earth Syst. Sci. Data, 13, 491-514, https://doi.org/10.5194/essd-13-491-2021, 2021.

1140 Stevens, B., Farrell, D., Hirsch, L., Jansen, F., Nuijens, L., Serikov, I., Brügmann, B., Forde, M., Linne, H., Lonitz, K., and Prospero, J. M.: The Barbados Cloud Observatory: Anchoring investigations of clouds and circulation on the edge of the ITCZ, Bull. Am. Meteorol. Soc., 97, 787-801, https://journals.ametsoc.org/view/journals/bams/97/5/bams-d-14-00247.1.xml, 2016.

1145 Stevens B., Brogniez H., Kiemle C., Lacour JL., Crevoisier C., Kiliani J.: Structure and dynamical influence of water vapor in the lower tropical troposphere. in: Shallow Clouds, Water Vapor, Circulation, and Climate Sensitivity (Space Sciences Series of ISSI), edited by: Pincus R., Winker D., Bony S., Stevens B., Springer, Cham, Switzerland,199-226, https://doi.org/10.1007/978-3-319-77273-8_10, 2017.

1150 Stevens, B., Bony, S., Farrell, D., Ament, F., Blyth, A., Fairall, C., Karstensen, J., Quinn, P. K., Speich, S., Acquistapace, C., Aemisegger, F., Albright, A. L., Bellenger, H., Bodenschatz, E., Caesar, K.-A., Chewitt-Lucas, R., de Boer, G., Delanoë, J., Denby, L., Ewald, F., Fildier, B., Forde, M., George, G., Gross, S., Hagen, M., Hausold, A., Heywood, K. J., Hirsch, L., Jacob, M., Jansen, F., Kinne, S., Klocke, D., Kölling, T., Konow, H., Lothon, M., Mohr, W., Naumann, A. K., Nuijens, L., Olivier, L., Pincus, R., Pöhlker, M., Reverdin, G., Roberts, G., Schnitt, S.,

1155 Schulz, H., Siebesma, A. P., Stephan, C. C., Sullivan, P., Touzé-Peiffer, L., Vial, J., Vogel, R., Zuidema, P., Alexander, N., Alves, L., Arixi, S., Asmath, H., Bagheri, G., Baier, K., Bailey, A., Baranowski, D., Baron, A., Barrau, S., Barrett, P. A., Batier, F., Behrendt, A., Bendinger, A., Beucher, F., Bigorre, S., Blades, E., Blossey, P., Bock, O., Böing, S., Bosser, P., Bourras, D., Bouruet-Aubertot, P., Bower, K., Branellec, P., Branger, H., Brennek, M., Brewer, A., Brilouet , P.-E., Brügmann, B., Buehler, S. A., Burke, E., Burton, R., Calmer, R., Canonici, J.-C.,

1160 Carton, X., Cato Jr., G., Charles, J. A., Chazette, P., Chen, Y., Chilinski, M. T., Choularton, T., Chuang, P., Clarke, S., Coe, H., Cornet, C., Coutris, P., Couvreux, F., Crewell, S., Cronin, T., Cui, Z., Cuypers, Y., Daley, A., Damerell, G. M., Dauhut, T., Deneke, H., Desbios, J.-P., Dörner, S., Donner, S., Douet, V., Drushka, K., Dütsch, M., Ehrlich, A., Emanuel, K., Emmanouilidis, A., Etienne, J.-C., Etienne-Leblanc, S., Faure, G., Feingold, G., Ferrero, L., Fix, A., Flamant, C., Flatau, P. J., Foltz, G. R., Forster, L., Furtuna, I., Gadian, A., Galewsky, J., Gallagher, M., 
1165 Gallimore, P., Gaston, C., Gentemann, C., Geyskens, N., Giez, A., Gollop, J., Gouirand, I., Gourbeyre, C., de Graaf, D., de Groot, G. E., Grosz, R., Güttler, J., Gutleben, M., Hall, K., Harris, G., Helfer, K. C., Henze, D., Herbert, C., Holanda, B., Ibanez-Landeta, A., Intrieri, J., Iyer, S., Julien, F., Kalesse, H., Kazil, J., Kellman, A., Kidane, A. T., Kirchner, U., Klingebiel, M., Körner, M., Kremper, L. A., Kretzschmar, J., Krüger, O., Kumala, W., Kurz, A., L'Hégaret, P., Labaste, M., Lachlan-Cope, T., Laing, A., Landschützer, P., Lang, T., Lange, D., Lange, I., Laplace,

1170 C., Lavik, G., Laxenaire, R., Le Bihan, C., Leandro, M., Lefevre, N., Lena, M., Lenschow, D., Li, Q., Lloyd, G., Los, S., Losi, N., Lovell, O., Luneau, C., Makuch, P., Malinowski, S., Manta, G., Marinou, E., Marsden, N., Masson, S., Maury, N., Mayer, B., Mayers-Als, M., Mazel, C., McGeary, W., McWilliams, J. C., Mech, M., Mehlmann, M., Meroni, A. N., Mieslinger, T., Minikin, A., Minnett, P., Möller, G., Morfa Avalos, Y., Muller, C., Musat, I., Napoli, A., Neuberger, A., Noisel, C., Noone, D., Nordsiek, F., Nowak, J. L., Oswald, L., Parker, D. J.,

1175 Peck, C., Person, R., Philippi, M., Plueddemann, A., Pöhlker, C., Pörtge, V., Pöschl, U., Pologne, L., Posyniak, M., Prange, M., Quiñones Meléndez, E., Radtke, J., Ramage, K., Reimann, J., Renault, L., Reus, K., Reyes, A., Ribbe, J., Ringel, M., Ritschel, M., Rocha, C. B., Rochetin, N., Röttenbacher, J., Rollo, C., Royer, H., Sadoulet, P., Saffin, L., Sandiford, S., Sandu, I., Schäfer, M., Schemann, V., Schirmacher, I., Schlenczek, O., Schmidt, J., Schröder, M., Schwarzenboeck, A., Sealy, A., Senff, C. J., Serikov, I., Shohan, S., Siddle, E., Smirnov, A., Späth, F., Spooner, B., 1180 Stolla, M. K., Szkółka, W., de Szoeke, S. P., Tarot, S., Tetoni, E., Thompson, E., Thomson, J., Tomassini, L., Totems, J., Ubele, A. A., Villiger, L., von Arx, J., Wagner, T., Walther, A., Webber, B., Wendisch, M., Whitehall, S., Wiltshire, A., Wing, A. A., Wirth, M., Wiskandt, J., Wolf, K., Worbes, L., Wright, E., Wulfmeyer, V., Young, S., Zhang, C., Zhang, D., Ziemen, F., Zinner, T., and Zöger, M.: EUREC4A, Earth Syst. Sci. Data, 13, 4067-4119, https://doi.org/10.5194/essd-13-4067-2021, 2021.

1185

Thurnherr, I., Kozachek, A., Graf, P., Weng, Y., Bolshiyanov, D., Landwehr, S., Pfahl, S., Schmale, J., Sodemann, H., Steen-Larsen, H. C., Toffoli, A., Wernli, H., and Aemisegger, F.: Meridional and vertical variations of the water vapour isotopic composition in the marine boundary layer over the Atlantic and Southern Ocean, Atmos. Chem. Phys., 20, 5811-5835, https://doi.org/10.5194/acp-20-5811-2020, 2020.

1190

Veefkind, J. P., Aben, I., McMullan, K., Förster, H., de Vries, J., Otter, G., Claas, J., Eskes, H. J., de Haan, J. F., Kleipool, Q., van Weele, M., Hasekamp, O., Hoogeveen, R., Landgraf, J., Snel, R., Tol, P., Ingmann, P., Voors, R., Kruizinga, B., Vink, R., Visser, H., and Levelt, P. F.: TROPOMI on the ESA Sentinel-5 Precursor: A GMES mission for global observations of the atmospheric composition for climate, air quality and ozone layer applications,

1195 Remote Sens. Environ., 120, 70-83, https://doi.org/10.1016/j.rse.2011.09.027, 2012.

Villiger, L., Wernli, H., Böttcher, M., Hagen, M., and Aemisegger, F., Lagrangian formation pathways of moist anomalies in the trade-wind region during the dry season: two case studies from EUREC4A, Weather Clim. Dynam. Discuss., https://doi.org/10.5194/wcd-2021-42, in review, 2021a.

Villiger, L., Dütsch, M., Jansen, F., Mech, M., and Aemisegger, F.: Calibrated stable water vapour isotope measurements from the BCO during EUREC4A [data set], Aeris, https://doi.org/10.25326/245, 2021b.

Villiger, L., Aemisegger, F., Reverdin, G., Demange, J., and Speich, S.: Calibrated stable water vapour isotope 1205 measurements on board RV Atalante during EUREC4A-OA [data set], Aeris, https://doi.org/10.25326/304, 2021c.

Villiger, L., Herbstritt, B., Ringel, M., Stolla, M. K., Mech, M., Jansen, F., and Aemisegger, F.: Calibrated stable water isotope data in precipitation from the BCO during EUREC4A [data set], Aeris, https://doi.org/10.25326/242, 2021d.

1210

Villiger, L., Aemisegger, F., Reverdin, G., Demange, J., and Speich, S.: Calibrated stable water isotope in precipitation from the RV Atalante during EUREC4A-OA [data set], Aeris, https://doi.org/10.25326/305, 2021 e. 
Villiger, L., Herbstritt, B., Acquistapace, C., Böck, T., \& Aemisegger, F.: Calibrated stable water isotope data in precipitation from the R/V Maria Sybilla Merian during EUREC4A [data set], Aeris, https://doi.org/10.25326/243, $2021 \mathrm{f}$.

waterisotopes-CISE-LOCEAN: Water isotopes of sea water analyzed since 1998 at LOCEAN [data set], SEANOE, https://doi.org/10.17882/71186, 2021.

1220

Weng, Y., Touzeau, A., and Sodemann, H.: Correcting the impact of the isotope composition on the mixing ratio dependency of water vapour isotope measurements with cavity ring-down spectrometers, Atmos. Meas. Tech., 13, 3167-3190, https://doi.org/10.5194/amt-13-3167-2020, 2020.

1225 Worden, J., Noone, D., Bowman, K., and Tropospheric Emission Spectrometer Science Team and Data contributors: Importance of rain evaporation and continental convection in the tropical water cycle, Nature, 445, 528-532, doi: 10.1038/nature05508, 2007.

Worden, J. R., Kulawik, S. S., Fu, D., Payne, V. H., Lipton, A. E., Polonsky, I., He, Y., Cady-Pereira, K., Moncet, 1230 J.-L., Herman, R. L., Irion, F. W., and Bowman, K. W.: Characterization and evaluation of AIRS-based estimates of the deuterium content of water vapor, Atmos. Meas. Tech., 12, 2331-2339, https://doi.org/10.5194/amt-12-23312019, 2019. 


\section{Tables}

Table 1. Bulk uncertainty estimates (in units \%) for precipitation and seawater isotope ratios.

$\begin{array}{lcc}\begin{array}{l}\text { Platform } \\ \text { BCO }\end{array} & \boldsymbol{\delta}^{\mathbf{1 8}} \mathbf{O} & \boldsymbol{\delta} \mathbf{D} \\ \quad \text { precipitation } & 0.16 & 0.60 \\ \begin{array}{l}\text { Meteor } \\ \quad \text { precipitation }\end{array} & 0.20 & 0.51 \\ \quad \text { seawater } & 0.23 & 0.56 \\ \text { Brown } & & \\ \quad \text { precipitation } & 0.20 & 0.80 \\ \quad \text { seawater } & -- & -- \\ \text { Atalante } & & \\ \quad \text { precipitation } & 0.16 & 0.60 \\ \quad \text { seawater } & \leqq 0.1 & \leqq 0.15 \\ \text { Merian } & & \\ \quad \text { precipitation } & 0.16 & 0.60\end{array}$

1240 Table 2. Root mean square error (RMSE) and Pearson correlation coefficients (CORR) for hourly mean comparisons between the BCO CRDS time series and the time series of three other analyzers. Meteor data were shifted by $9 \mathrm{~h}$ and Atalante data were shifted by 10 minutes to account for the geographic distance between measurement sites.

\begin{tabular}{|c|c|c|c|c|c|c|}
\hline Analyzer & $\begin{array}{c}\text { Period } \\
{[\mathbf{U T C}]}\end{array}$ & Statistic & $\begin{array}{c}\mathbf{q} \\
{[\mathbf{g} / \mathbf{k g}]}\end{array}$ & $\begin{array}{c}\boldsymbol{\delta}^{\mathbf{1 8}} \mathbf{O} \\
{[\% \mathbf{0}]}\end{array}$ & $\begin{array}{c}\boldsymbol{\delta} \mathbf{D} \\
{[\% \mathbf{0}]}\end{array}$ & $\begin{array}{c}\boldsymbol{d} \\
{[\% \mathbf{o}]}\end{array}$ \\
\hline \multirow{2}{*}{$\begin{array}{c}\text { BCO OA- } \\
\text { ICOS }\end{array}$} & $\begin{array}{c}20 \mathrm{Jan} \\
-\end{array}$ & RMSE & 0.51 & 1.53 & 4.61 & 7.83 \\
\cline { 2 - 7 } & $15 \mathrm{Feb}$ & CORR & 1.00 & 0.63 & 0.94 & 0.41 \\
\hline \multirow{2}{*}{ Meteor } & $\begin{array}{c}20 \mathrm{Jan} \\
-\end{array}$ & RMSE & 1.15 & 1.06 & 4.35 & 4.55 \\
\cline { 2 - 7 } & $15 \mathrm{Feb}$ & CORR & 0.46 & 0.47 & 0.40 & 0.51 \\
\hline \multirow{2}{*}{ Atalante } & $17 \mathrm{Feb}$ & RMSE & 0.89 & 0.96 & 1.79 & 5.30 \\
\cline { 2 - 7 } & $0000-0500$ & CORR & 0.97 & 0.58 & 0.86 & 0.50 \\
\hline
\end{tabular}


Table 3. EUREC ${ }^{4} \mathrm{~A}$-iso in situ and remotely sensed data sets.

\begin{tabular}{|c|c|c|c|}
\hline \multicolumn{4}{|l|}{ Water vapor } \\
\hline Data set & Link & Citation & Notes \\
\hline BCO CRDS & $\begin{array}{l}\text { https://doi.org/10.25326/ } \\
\underline{245}\end{array}$ & Villiger et al. (2021b) & $\begin{array}{l}1 \text { minute resolution, } \mathrm{H}_{2} \mathrm{O} \text { provided as a dry mole } \\
\text { fraction and specific humidity }\end{array}$ \\
\hline BCO OA-ICOS & \begin{tabular}{|l|} 
https://doi.org/10.25326/ \\
309
\end{tabular} & Galewsky (2020a) & $\begin{array}{l}1 \text { minute resolution, } \mathrm{H}_{2} \mathrm{O} \text { provided as a wet mole } \\
\text { fraction and specific humidity }\end{array}$ \\
\hline ATR & \begin{tabular}{|l|}
$\underline{\text { htps://doi.org/10.25326/ }}$ \\
$\underline{4}$
\end{tabular} & $\begin{array}{l}\text { Aemisegger et al. } \\
(2021 b)\end{array}$ & $\begin{array}{l}1 \text { second resolution, } \mathrm{H}_{2} \mathrm{O} \text { provided as a dry mole } \\
\text { fraction and specific humidity, YAML files flag } \\
\text { poor quality data }\end{array}$ \\
\hline $\mathrm{P}-3$ & $\begin{array}{l}\text { https://doi.org/10.25921/ } \\
\text { c5yx-7w29 }\end{array}$ & Bailey et al. (2020) & $\begin{array}{l}1 \text { second resolution, } \mathrm{H}_{2} \mathrm{O} \text { archived separately as a } \\
\text { wet mole fraction and (dry) mass mixing ratio (see } \\
\text { Pincus et al. 2021), quality-control flag provided } \\
\text { for } \delta 18 \mathrm{O} \text {, sample-rate data also available }\end{array}$ \\
\hline Meteor & 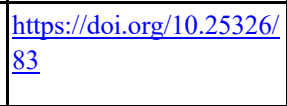 & Galewsky (2020b) & $\begin{array}{l}1 \text { minute resolution, } \mathrm{H}_{2} \mathrm{O} \text { provided as a wet mole } \\
\text { fraction and specific humidity, flag for } \\
\text { precipitation periods available upon request }\end{array}$ \\
\hline Brown & \begin{tabular}{|l|} 
https://doi.org/10.25921/ \\
s76r-1n85
\end{tabular} & $\begin{array}{l}\text { Bailey and Noone } \\
(2021)\end{array}$ & $\begin{array}{l}1 \text { minute resolution, } \mathrm{H}_{2} \mathrm{O} \text { provided as a wet mole } \\
\text { fraction, specific humidity, and (dry) mass mixing } \\
\text { ratio, flags for contamination and inlet reversal } \\
\text { periods provided }\end{array}$ \\
\hline Atalante & $\begin{array}{l}\text { https://doi.org/10.25326/ } \\
\underline{304}\end{array}$ & Villiger et al. (2021c) & $\begin{array}{l}2 \text { minute resolution, } \mathrm{H}_{2} \mathrm{O} \text { provided as a wet mole } \\
\text { fraction and specific humidity, temperature and } \\
\text { salinity at } 5 \mathrm{~m} \text { depth included, flags for quality } \\
\text { control and precipitation periods provided }\end{array}$ \\
\hline IASI & $\begin{array}{l}\text { https://doi.org/10.25326/ } \\
\underline{262}\end{array}$ & Diekmann et al. (2021b) & $\begin{array}{l}\text { Full vertical profiles provided for the } 10^{\circ} \times 10^{\circ} \\
\text { box defined by } 5^{\circ}-15^{\circ} \mathrm{N} \text { and } 50^{\circ}-60^{\circ} \mathrm{W} \text {, select } \\
\text { levels provided for the extended region } 21^{\circ} \mathrm{S}-54^{\circ} \\
\mathrm{N} \text { and } 110^{\circ} \mathrm{W}-22^{\circ} \mathrm{E}, \mathrm{H}_{2} \mathrm{O} \text { provided as a dry } \\
\text { mole fraction, full dataset accessible from } \\
\text { https://dx.doi.org/10.35097/415 }\end{array}$ \\
\hline TROPOMI & $\begin{array}{l}\text { https://doi.org/10.25326/ } \\
\underline{306}\end{array}$ & $\begin{array}{l}\text { Schneider and Borsdorff } \\
(2021)\end{array}$ & $\begin{array}{l}\text { Total column information provided for the region } \\
21^{\circ} \mathrm{S}-54^{\circ} \mathrm{N} \text { and } 110^{\circ} \mathrm{W}-22^{\circ} \mathrm{E} \text {, full dataset } \\
\text { accessible from } \\
\text { https://tropomi.grid.surfsara.nl/hdo/ }\end{array}$ \\
\hline
\end{tabular}

\begin{tabular}{|c|c|c|c|}
\hline \multicolumn{4}{|c|}{ Rainwater } \\
\hline Data set & Link & Citation & Notes \\
\hline $\mathrm{BCO}$ & \begin{tabular}{|l}
$\underline{\text { https://doi.org/10.25326/ }}$ \\
242
\end{tabular} & Villiger et al. (2021d) & $\begin{array}{l}\text { Event-based except for intensive sampling of a } \\
\text { front, rainfall amount and quality-control flags } \\
\text { included }\end{array}$ \\
\hline Meteor & \begin{tabular}{|l} 
https://doi.org/10.25326/ \\
308
\end{tabular} & Galewsky (2020c) & Event-based \\
\hline Brown & $\begin{array}{l}\text { https://doi.org/10.25921/ } \\
\text { bbje-6y41 (in progress, } \\
\text { see Supplemental } \\
\text { Information for a copy } \\
\text { of the data) }\end{array}$ & $\begin{array}{l}\text { Quiñones Meléndez et } \\
\text { al. (2021) }\end{array}$ & $\begin{array}{l}\text { Event-based, possible concerns include } \\
\text { evaporative enrichment due to delayed collections } \\
\text { from the sampler and sea spray contamination, } \\
\text { flag for substantially delayed collection times } \\
\text { included }\end{array}$ \\
\hline Atalante & $\frac{\text { https://doi.org/10.25326/ }}{305}$ & Villger et al. (2021e) & $\begin{array}{l}\text { Event-based, rainfall collection times are not } \\
\text { exact, sample \#1 appears unphysical }\end{array}$ \\
\hline
\end{tabular}




\begin{tabular}{|l|l|l|l|}
\hline Merian & https://doi.org/10.25326/ & Villiger et al. (2021f) & Event-based, quality-control flags included \\
\hline$\underline{243}$ & & \\
\hline
\end{tabular}

\begin{tabular}{|c|c|c|c|}
\hline \multicolumn{4}{|c|}{ Seawater } \\
\hline Data set & Link & Citation & Notes \\
\hline Meteor & https://doi.org/10.25326/ & Galewsky (2020d) & $\begin{array}{l}\text { Near-daily at } 10 \mathrm{~m} \text { depth, except for intensive } \\
\text { sampling of a diurnal period }\end{array}$ \\
\hline Brown & $\begin{array}{l}\text { Preliminary data } \\
\text { provided in } \\
\text { Supplemental } \\
\text { Information }\end{array}$ & -- & $\begin{array}{l}\text { Sub-daily at variable depths, laboratory analysis of } \\
\text { samples is still in progress as of this writing }\end{array}$ \\
\hline Atalante & $\frac{\text { https://doi.org/10.17882/ }}{71186}$ & $\begin{array}{l}\text { waterisotopes-CISE- } \\
\text { LOCEAN (2021) }\end{array}$ & $\begin{array}{l}\text { Sub-daily at variable depths, temperature, salinity, } \\
\text { and quality-control flags included }\end{array}$ \\
\hline
\end{tabular}

Figures

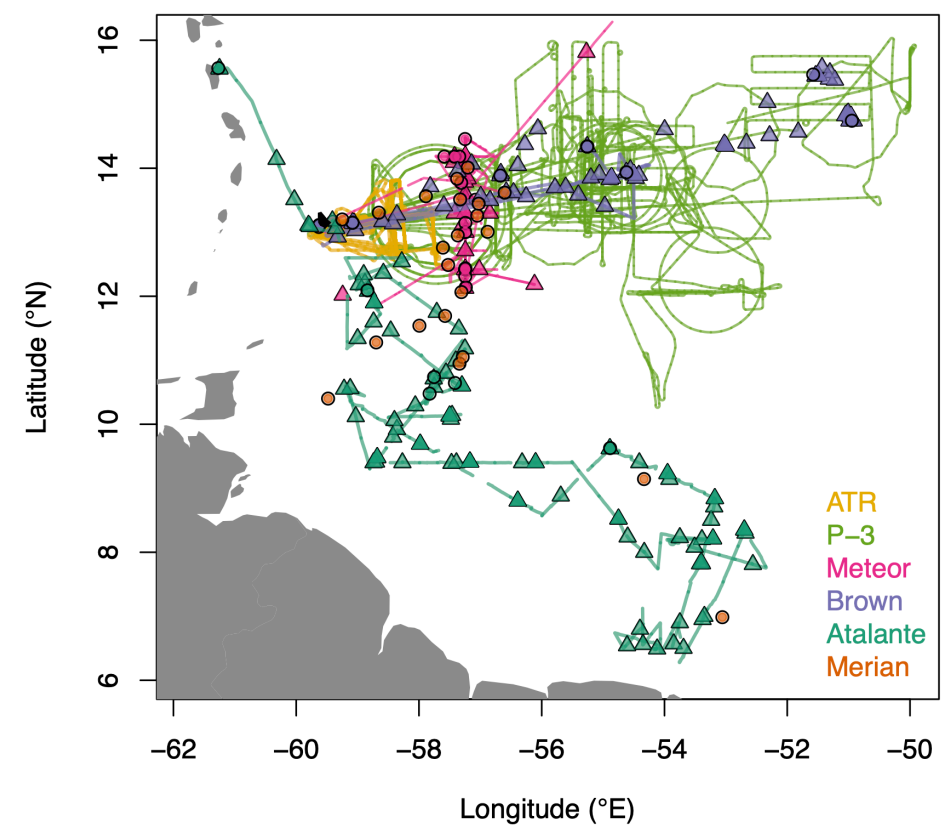

1255 Figure 1: Map of continuous (water vapor) and discrete (rain and seawater) isotopic sampling during the EUREC $\mathrm{C}^{4} \mathrm{~A} 2020$ field experiment. Tracks for the various aircraft and ships are plotted only for periods during which water vapor isotopic sampling occurred. Circles and triangles indicate locations of rain and seawater sampling, respectively. Barbados appears in black. 


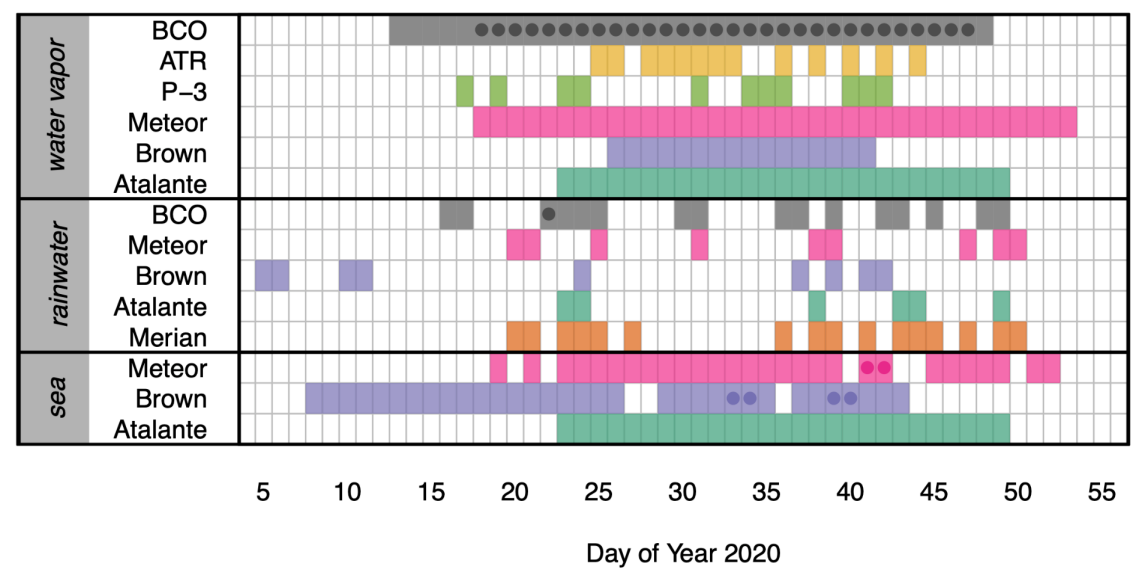

Figure 2: Timeline of continuous (water vapor) and discrete (rain and seawater) isotopic sampling during EUREC ${ }^{4} \mathrm{~A}$. Dots either represent days when two laser analyzers were operating at BCO or indicate intensive observation periods for rain or sea water (see main text for additional details). Discrete samples are represented by their collection times, which, in the case of Brown rainwater, were delayed in some cases by up to several days following precipitation.

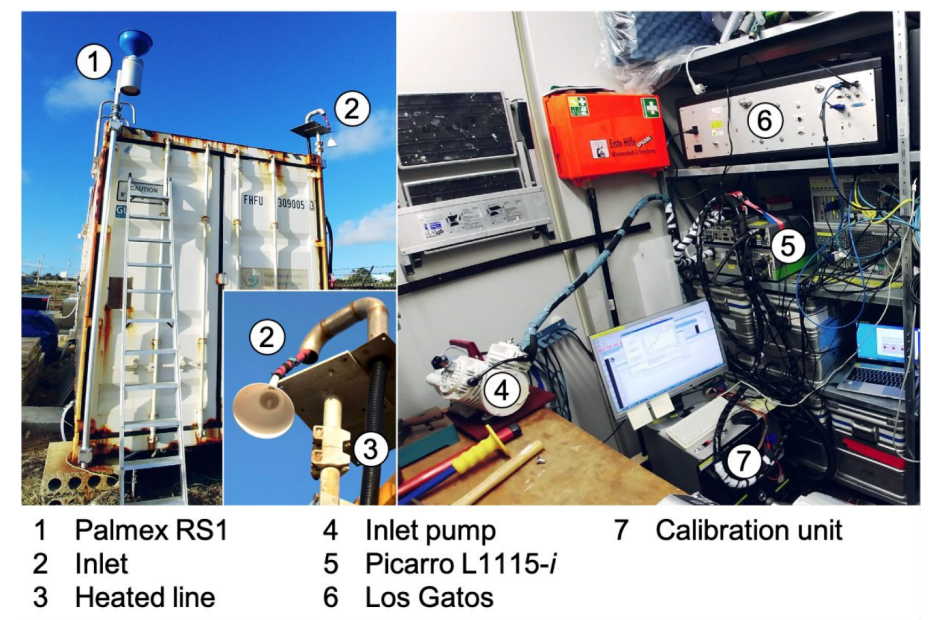

Figure 3: Isotopic sampling installations at the Barbados Cloud Observatory were comprised of a Palmex RS1 rainwater collector (\#1) and two water vapor isotopic analyzers (fabricated by Picarro (\#5) and Los Gatos Research (\#6)). 
https://doi.org/10.5194/essd-2022-3

Preprint. Discussion started: 31 January 2022

(c) Author(s) 2022. CC BY 4.0 License. a.

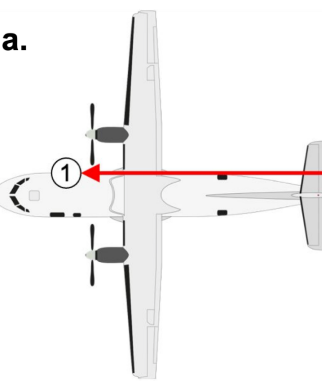

1 Inlet

2 Heated line

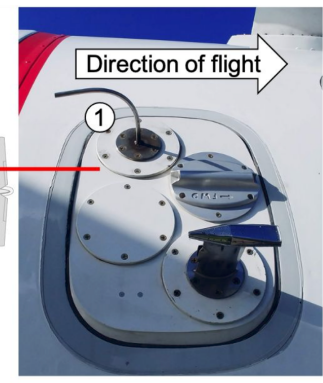

3 Calibration unit

4 Isotopic analyzer

b.

b.

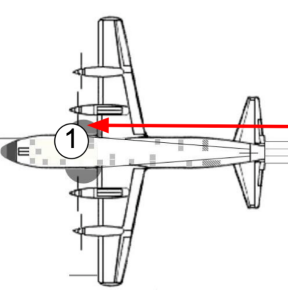

1 Backwards facing inlet 2 Inlet housing

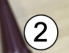

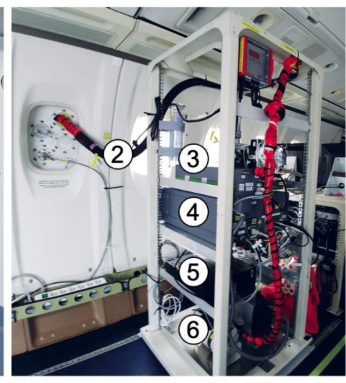

5 Uninterruptible power supply 6 Pumps

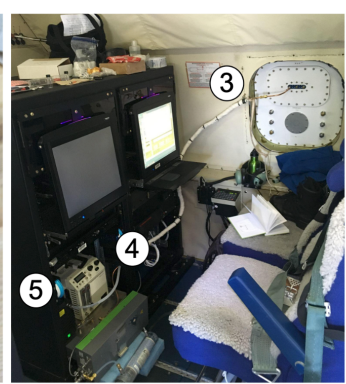

5 Calibration system

Figure 4: Water vapor isotopic sampling installations on the a) ATR and b) P-3 aircraft. (ATR schematic downloaded from https://t3projects.mpimet.mpg.de/coordination/platform-schematics. P3 schematic provided by NOAA.) 
https://doi.org/10.5194/essd-2022-3

Preprint. Discussion started: 31 January 2022

(c) Author(s) 2022. CC BY 4.0 License.

a.

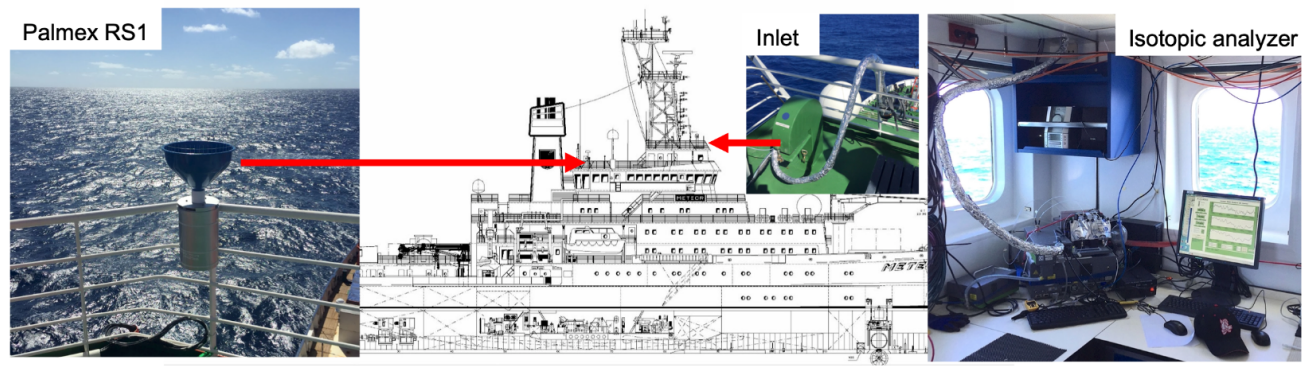

b.

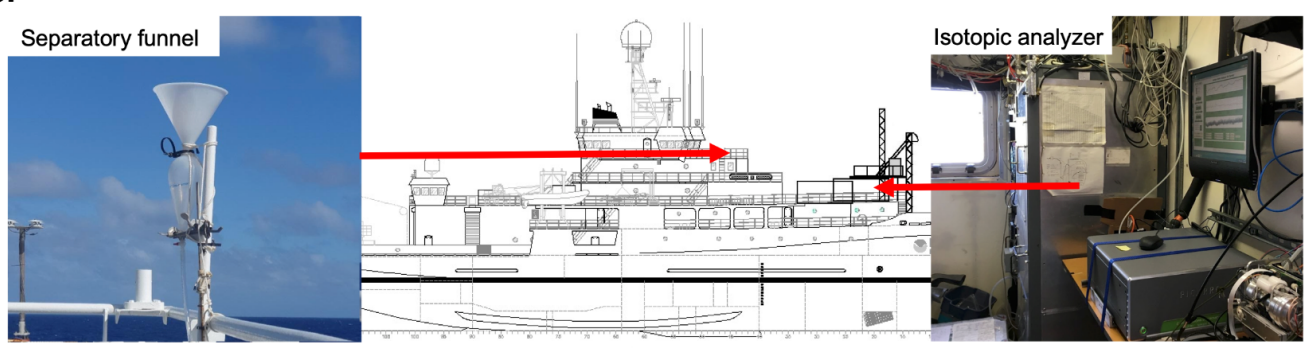

c.

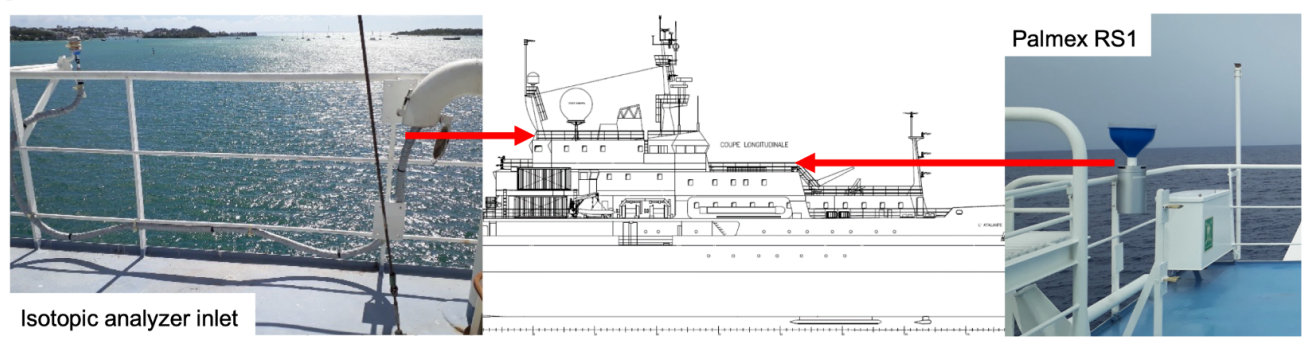

d.

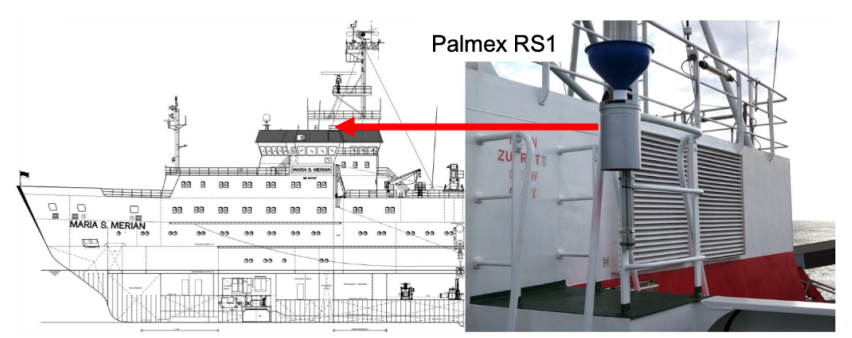

Figure 5: Water isotopic sampling installations aboard a) the Meteor, b) the Brown, c) the Atalante, and d) the Merian. (Meteor and Merian ship schematics provided by University of Hamburg. Brown ship schematic provided by NOAA. Atalante ship schematic copyright @Ifremer. Atalante photos courtesy of Jérôme Demange.) 


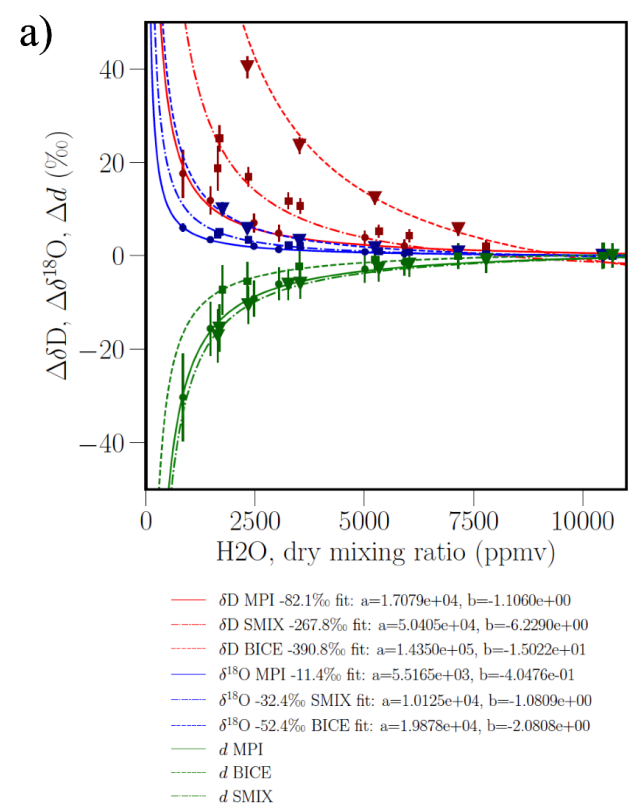

b)

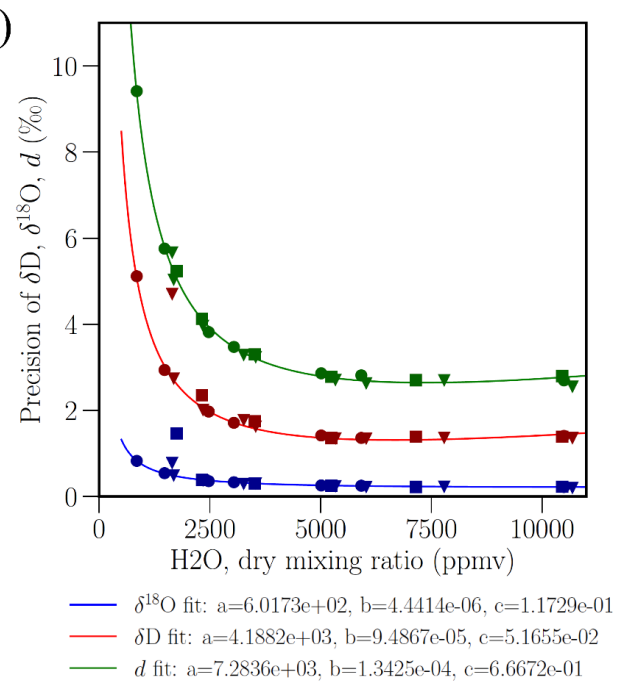
Figure 6: Bias corrections and uncertainties associated with the ATR water vapor isotopic measurements: a) symbols
illustrate the humidity dependence of the isotopic measurements for three distinct liquid standards (MPI, SMIX, BICE) while lines show the correction functions used to remove the detected biases; b) precision of the isotopic measurements as a function of the measured water vapor concentration. 

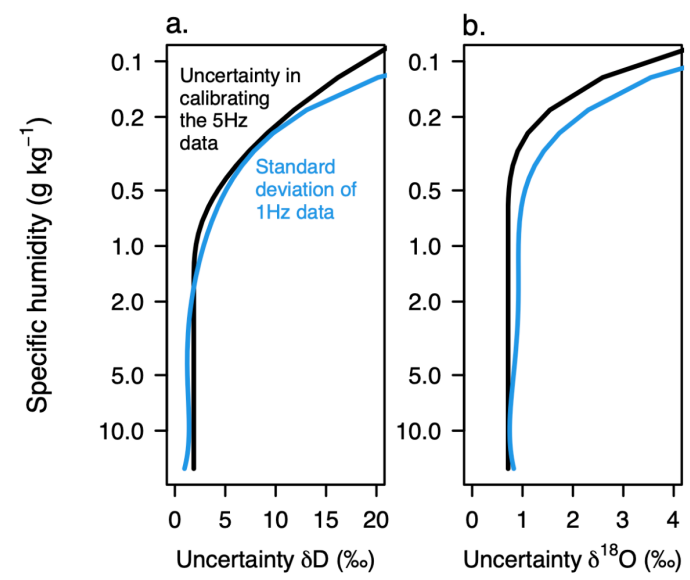

1290 Figure 7: P-3 isotopic uncertainties ( $x$-axis) plotted as a function of specific humidity ( $y$-axis). The $y$-axis is plotted on a logarithmic scale to convey the approximate uncertainties of the vertical profiles measured by the aircraft. Black lines indicate uncertainties associated with the normalization of the $5 \mathrm{~Hz}$ data to the VSMOW-SLAP scale. Blue lines represent the standard deviations associated with the $1 \mathrm{~Hz}$ averages from the first two research flights: they reflect both the variability of the environment and the additional imprecision of the isotopic analyzer in flight.

a.

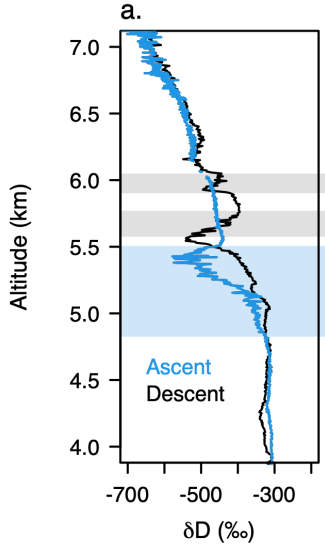

b.

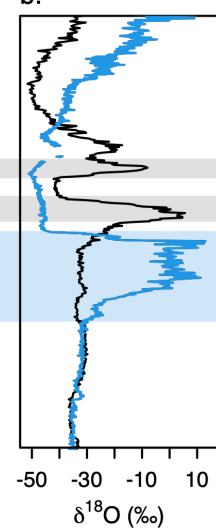

c.

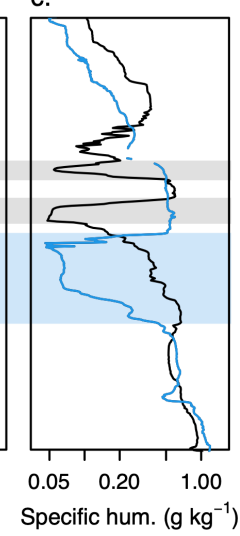

Figure 8: Strong hysteresis causes (a) the $\delta \mathrm{D}$ vertical profile to differ substantially from vertical profiles of (b) $\boldsymbol{\delta}^{18} \mathrm{O}$ and (c) specific humidity during P-3 Research Flight 8. Three dry layers, in which the delayed response and weaker signal in $\delta \mathrm{D}$ are most evident, are indicated by shading. Signal delay is most evident on the descending profile (black). $\delta^{18} \mathrm{O}$ is characterized by a better time response than $\delta \mathrm{D}$ but shows unphysical enrichment at altitude due to a shifting humiditydependent bias over the course of the campaign. 
https://doi.org/10.5194/essd-2022-3

Preprint. Discussion started: 31 January 2022

(c) Author(s) 2022. CC BY 4.0 License.
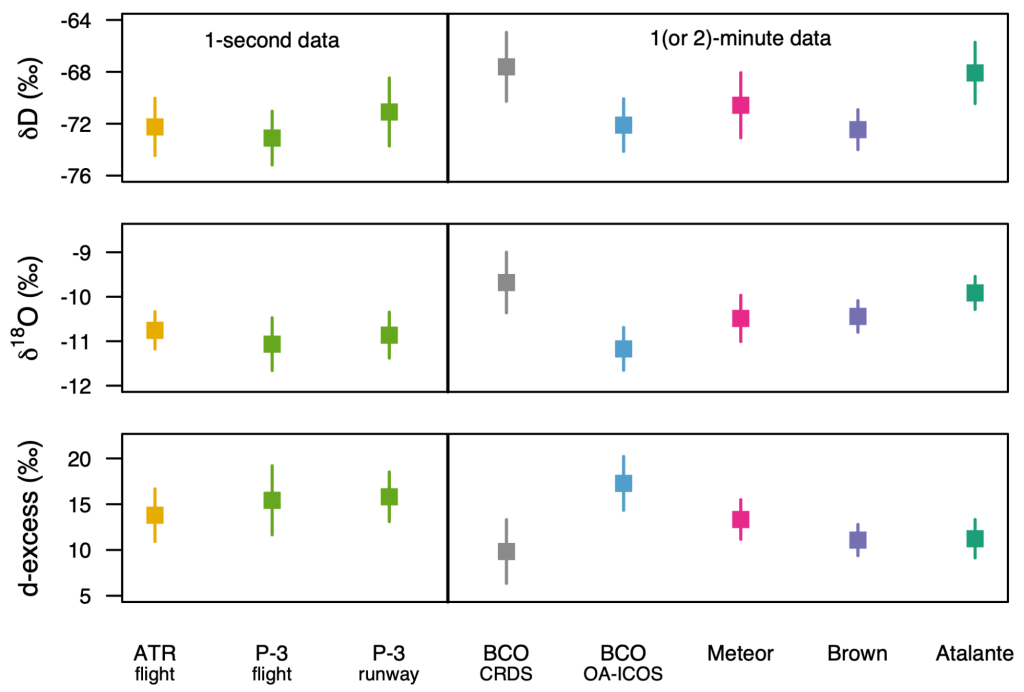

Figure 9: Campaign-mean near-surface water vapor isotopic values from the various ground, airborne, and ship-based platforms. Whiskers represent standard deviations. Values from in flight represent a height of $150 \pm 15$ m.a.s.l. Only nonflagged data included in the comparison.
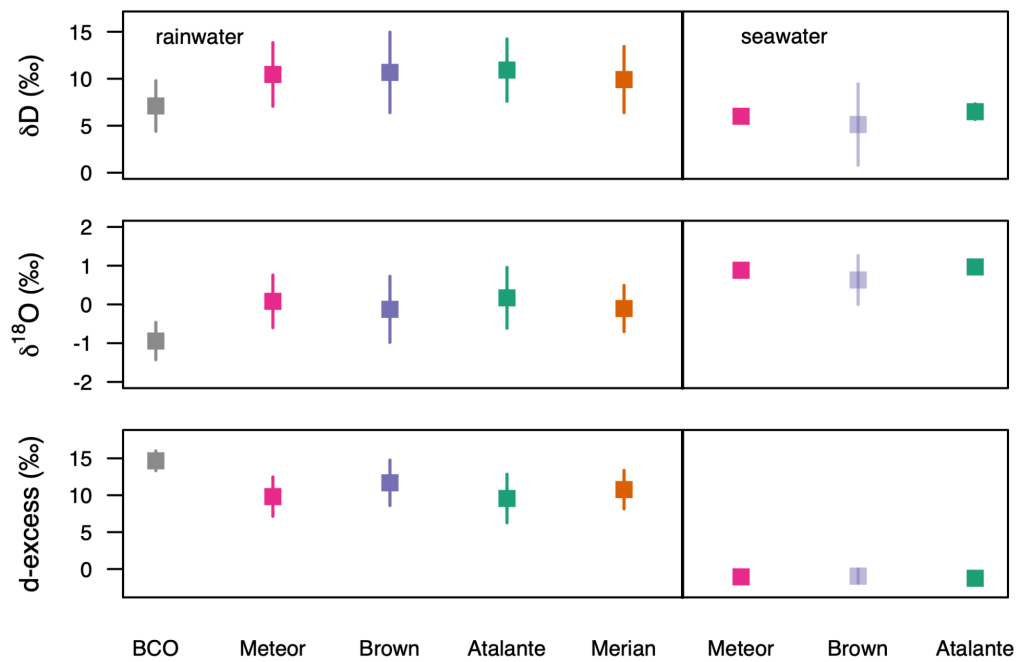

Figure 10: Campaign-mean rainwater and seawater values from the $\mathrm{BCO}$ and ship-based platforms. Whiskers represent standard deviations. Flagged samples and seawater samples taken from a depth greater than $10 \mathrm{~m}$ are excluded from the comparison. Brown seawater values are still preliminary and laboratory analysis of Brown seawater ongoing. 

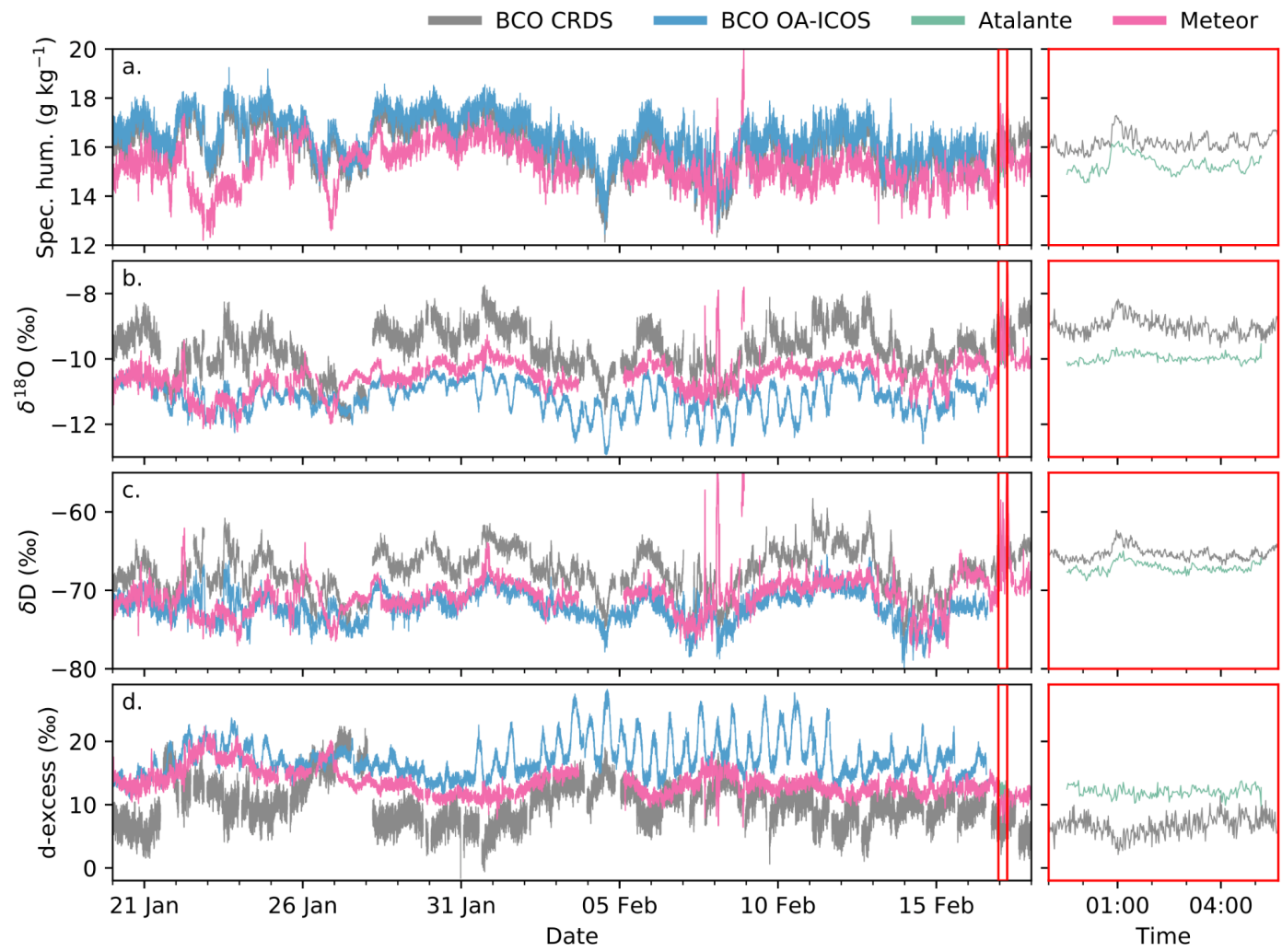

Figure 11: Time series of (a) water vapor concentration, (b) $\boldsymbol{\delta}^{18} \mathrm{O}$, (c) $\delta \mathrm{D}$, and (d) $d$ from the BCO CRDS analyzer (gray), the BCO OA-ICOS analyzer (blue), and the Meteor (magenta) for the period 20 January to 17 February 2020 (DOY 2048). The Meteor trace is shifted by 9 hours. Rightmost panels show an enlarged view of the correlation between the BCO CRDS system and the Atalante (teal) for the period 23:30 16 Feb - 05:10 17 Feb UTC (DOY 47-48), when the Atalante was 1-3 nmi northeast of the BCO. The Atlante trace is shifted by 10 minutes. 

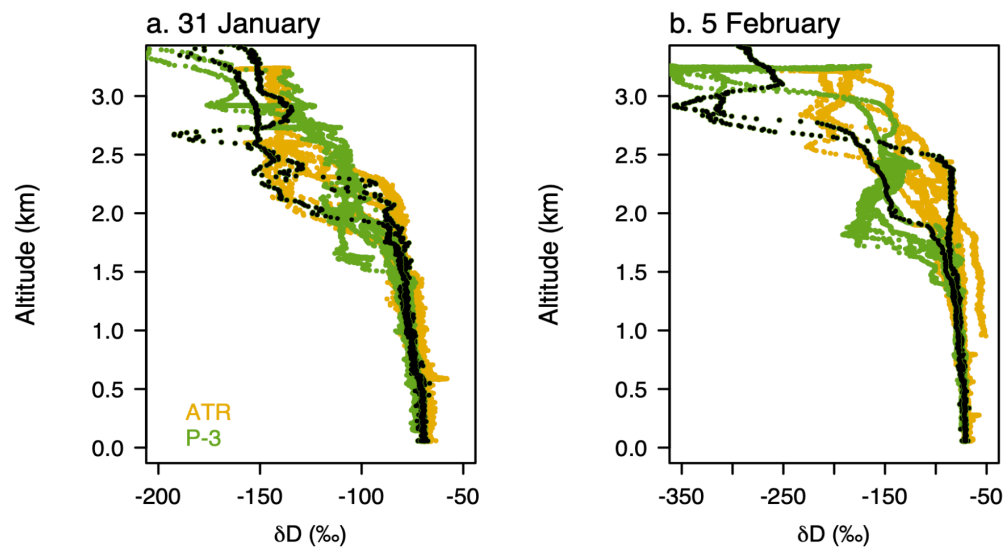

1325 Figure 12: Vertical $\delta$ D profiles from the ATR (yellow) and the P-3 (green) for (a) 31 January (DOY 31) and (b) 5 February (DOY 6), the two days on which both aircraft were in the air simultaneously. P-3 observations with black centers represent takeoffs and landings, which were flown in closest proximity to the ATR and show the greatest structural similarity to ATR $\delta D$ profiles.

a.

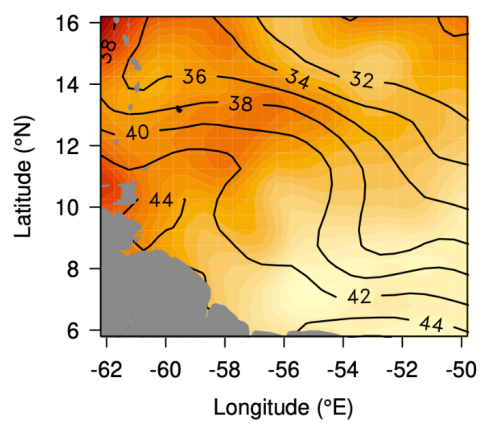

$\delta \mathrm{D}$

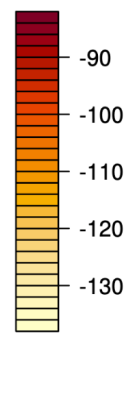

b.

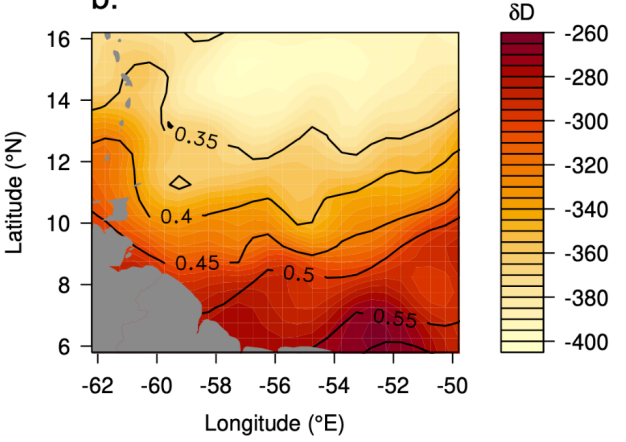

Figure 13: a) TROPOMI total column $\delta D$ (shading) and total column water ( $\mathrm{kg} \mathrm{m}^{2}$, contours), averaged on a 0.5-degree grid and smoothed for the period 11 Jan - 20 Feb 2020 (DOY 11-51). Only retrievals with a quality value of 0.5 or higher are selected. b) IASI $\delta D$ and specific humidity ( $\mathrm{g} \mathrm{kg}^{-1}$; contours) at $6.4 \mathrm{~km}$, averaged on a 0.5 -degree grid and smoothed for the same period. (Note that the two water vapor fields represent distinct quantities.) Only data marked "good quality" in terms of spectral fit are used. Barbados appears in black. 

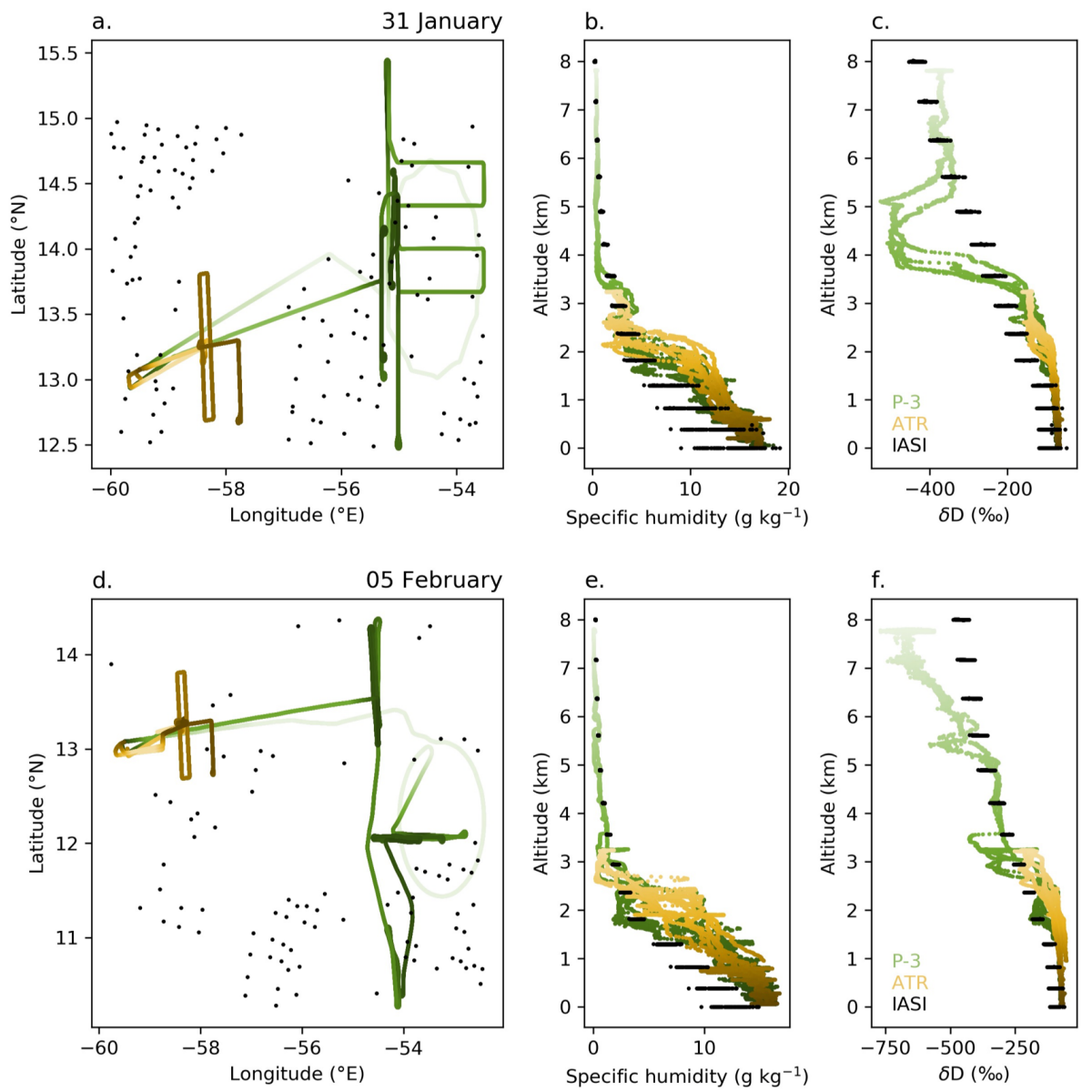

Figure 14: (a,d) Maps of the measurement locations for IASI (black, morning passes only), the ATR (yellow), and the P-3 (green) on (top) 31 January (DOY 31) and (bottom) 5 February 2020 (DOY 6) and measured vertical profiles of (b,e) specific humidity and $(c, f) \delta D$ from these days. 